\title{
Neuroinflammatory Dynamics Underlie Memory Impairments after Repeated Social Defeat
}

\author{
D.Daniel B. McKim, ${ }^{1,2 *}$ Anzela Niraula, ${ }^{1,2 *}$ Andrew J. Tarr, ${ }^{1,2}$ Eric S. Wohleb, ${ }^{1,2}$ John F. Sheridan, ${ }^{1,3,4}$ \\ and Jonathan P. Godbout ${ }^{2,3,4}$ \\ ${ }^{1}$ Division of Biosciences, ${ }^{2}$ Department of Neuroscience, ${ }^{3}$ Center for Brain and Spinal Cord Repair, and ${ }^{4}$ Institute for Behavioral Medicine Research, Ohio \\ State University, Columbus, Ohio 43210
}

Repeated social defeat (RSD) is a murine stressor that recapitulates key physiological, immunological, and behavioral alterations observed in humans exposed to chronic psychosocial stress. Psychosocial stress promotes prolonged behavioral adaptations that are associated with neuroinflammatory signaling and impaired neuroplasticity. Here, we show that RSD promoted hippocampal neuroinflammatory activation that was characterized by proinflammatory gene expression and by microglia activation and monocyte trafficking that was particularly pronounced within the caudal extent of the hippocampus. Because the hippocampus is a key area involved in neuroplasticity, behavior, and cognition, we hypothesize that stress-induced neuroinflammation impairs hippocampal neurogenesis and promotes cognitive and affective behavioral deficits. We show here that RSD caused transient impairments in spatial memory recall that resolved within $28 \mathrm{~d}$. In assessment of neurogenesis, the number of proliferating neural progenitor cells (NPCs) and the number of young, developing neurons were not affected initially after RSD. Nonetheless, the neuronal differentiation of NPCs that proliferated during RSD was significantly impaired when examined 10 and $28 \mathrm{~d}$ later. In addition, social avoidance, a measure of depressive-like behavior associated with caudal hippocampal circuitry, persisted $28 \mathrm{~d}$ after RSD. Treatment with minocycline during RSD prevented both microglia activation and monocyte recruitment. Inhibition of this neuroinflammatory activation in turn prevented impairments in spatial memory after RSD but did not prevent deficits in neurogenesis nor did it prevent the persistence of social avoidance behavior. These findings show that neuroinflammatory activation after psychosocial stress impairs spatial memory performance independent of deficits in neurogenesis and social avoidance.

Key words: macrophages; microglia; neurogenesis; neuroinflammation; social avoidance; stress

\section{Significance Statement}

Repeated exposure to stress alters the homeostatic environment of the brain, giving rise to various cognitive and mood disorders that impair everyday functioning and overall quality of life. The brain, previously thought of as an immune-privileged organ, is now known to communicate extensively with the peripheral immune system. This brain-body communication plays a significant role in various stress-induced inflammatory conditions, also characterized by psychological impairments. Findings from this study implicate neuroimmune activation rather than impaired neurogenesis in stress-induced cognitive deficits. This idea opens up possibilities for novel immune interventions in the treatment of cognitive and mood disturbances, while also adding to the complexity surrounding the functional implications of adult neurogenesis.

\section{Introduction}

Chronic psychological stress is a strong risk factor in the etiology of numerous mental health complications (McEwen, 2012), in-

\footnotetext{
Received June 17, 2015; revised Jan. 11, 2016; accepted Jan. 17, 2016.

Author contributions: D.B.M., A.N., E.S.W., J.F.S., and J.P.G. designed research; D.B.M., A.N., A.J.T., and E.S.W. performed research; J.F.S. and J.P.G. contributed unpublished reagents/analytic tools; D.B.M., A.N., A.J.T., and E.S.W. analyzed data; D.B.M., A.N., and J.P.G. wrote the paper.

This study was supported by National Institute of Health Grants R01-MH-093473 and R01-MH093472 (J.F.S.) and National Institute of Aging Grant R01-AG033028 (J.P.G.). D.B.M. was supported by National Institute of Dental and Craniofacial Research Training Grant T32-DE014320. We thank Daniel Shea and Kyle Atcheson for their technical assistance.

${ }^{*}$ D.B.M. and A.N. contributed equally to this work.

The authors declare no competing financial interests.
}

cluding mood disorders and cognitive impairments. Recent work reveals that chronic stress triggers immune dysfunction that is causally implicated in mental health disturbances (Glaser and Kiecolt-Glaser, 2005; Wohleb et al., 2014b; Reader et al., 2015). Individuals exposed to chronic stress show persistent cognitive

Correspondence should be addressed to either of the following: John F. Sheridan, 223 Institute for Behavioral Medicine Research Building, 460 Medical Center Drive, Columbus, OH 43210, E-mail: John.Sheridan@osumc.edu; or Jonathan Godbout, 259 Institute for Behavioral Medicine Research Building, 460 Medical Center Drive, Columbus, OH 43210, E-mail: Jonathan.Godbout@osumc.edu.

E. S. Wohleb's present address: Department of Psychiatry, Yale University School of Medicine, New Haven, CT 06519.

DOI:10.1523/JNEUROSCI.2394-15.2016

Copyright $\odot 2016$ the authors $\quad 0270-6474 / 16 / 362590-15 \$ 15.00 / 0$ 
and emotional dysregulation that contribute to deterioration of overall mental health and quality of life (Baum et al., 1993; McEwen, 2013). For instance, studies with caregivers (Caswell et al., 2003; Mackenzie et al., 2007) and college-age students (Keinan et al., 1999) demonstrate that chronic stress is associated strongly with cognitive impairments and accelerated cognitive decline (Vitaliano et al., 2011). Additional studies also report associations between stress-induced neuroinflammatory activation and psychological disturbances. For instance, elevated proinflammatory cytokines (Janelidze et al., 2011), increased microglia activation (Schnieder et al., 2014), and increased brain macrophages (Torres-Platas et al., 2014) were all detected within specific brain regions of depressed suicide victims. Thus, stressinduced neuropsychiatric disturbances may involve impaired neuroplasticity caused by microglia activation, monocyte recruitment, and enhanced neuroinflammatory signaling.

These connections between neuroimmune activation and psychological complications are also paralleled in rodent models of stress, such as repeated social defeat (RSD). In these models, sympathetic activation promotes the production of proinflammatory monocytes (Wohleb et al., 2011; Powell et al., 2013; Heidt et al., 2014) that traffic to the brain (Wohleb et al., 2011) and promote the development of prolonged and recurring anxiety (Wohleb et al., 2013, 2014a, McKim et al., 2015). In addition, chronic stressors activate microglia within specific stressresponsive brain regions (Tynan et al., 2010; Wohleb et al., 2011) that are spatially coupled to neurovascular facilitation of monocyte recruitment (Sawicki et al., 2015). These experimental findings reveal a profound, bidirectional interplay between stress circuitry and neuroimmune signaling that controls behavioral responses to chronic stress. Treatments, such as $\beta$-adrenergic receptor antagonists, benzodiazepines, and antidepressants, that modify neuronal adaptation prevent many of the neuroimmune and behavioral responses to psychosocial stress, including anxiety and social avoidance (Wohleb et al., 2011; Ramirez et al., 2015, 2016). Furthermore, treatments that interfere at the neuroimmune interface also prevent stress-induced behavioral adaptations, including prolonged and recurring anxiety (Wohleb et al., 2014a,c, McKim et al., 2015) and depressive-like behaviors (Kreisel et al., 2014). Thus, stress-induced neuroinflammatory responses serve as an important link between immune dysfunction and development of mood disorders.

In the RSD model, neuroinflammatory activation was localized primarily within the limbic system including the hippocampus (Wohleb et al., 2013). This is relevant because the hippocampus is a key area involved in neuroplasticity, behavior, and cognition (McEwen, 1999). Indeed, increased neuroinflammatory signaling augments neurobiological processes implicated in behavioral disorders involving neurogenesis (Koo and Duman, 2008) and metabolism of neurotransmitters (Miller et al., 2009; O'Connor et al., 2009). Corresponding with these findings, neuroinflammatory activation in the hippocampus may impair neuroplasticity and behavior after psychosocial stress.

Therefore, the objective of this study was to investigate whether stress-induced neuroinflammation (e.g., microglial activation, cytokine induction, and monocyte recruitment) affected hippocampal neurogenesis, cognition, and mood. Here, we show that RSD enhances neuroinflammation in the hippocampus, causes transient deficits in memory recall, alters neuronal cell fate, and prolongs social avoidance. Moreover, hippocampal-dependent memory deficits were caused by neuroinflammatory activation, whereas social avoidance and impaired neurogenesis were not. Collectively, these studies demonstrate a dichotomy of behaviors that are dependent and independent of stress-induced neuroinflammation.

\section{Materials and Methods}

Mice. Male C57BL/6 (6-8 weeks old) and male CD-1 retired breeder mice were purchased from Charles River and allowed to acclimate to their surroundings for 7-10 d before experiments. Mice were housed in $11.5 \times 7.5 \times$ 6-inch polypropylene cages. Rooms were maintained at $21^{\circ} \mathrm{C}$ under a $12 \mathrm{~h}$ light/dark cycle from 6:00 A.M. to 6:00 P.M. with ad libitum access to water and rodent chow. All experiments took place between 8:00 A.M. and 11:00 A.M., unless noted otherwise. All procedures were in accordance with the National Institutes of Health Guidelines for the Care and Use of Laboratory Animals and were approved by the Ohio State University Institutional Laboratory Animal Care and Use Committee.

$R S D$. RSD was performed as described previously (Wohleb et al., 2013). In brief, an aggressive male intruder $\mathrm{CD}-1$ mouse was introduced into cages of established male cohorts (three per cage) of C57BL/ 6 mice for $2 \mathrm{~h}$ between 5:00 P.M. and 7:00 P.M. for 6 consecutive nights. During each cycle, submissive behavior, including upright posture, fleeing, and crouching, were observed to ensure defeat of the resident mice. If the intruder did not initiate an attack within 5-10 min or was attacked by any of the resident mice, a new intruder was introduced. At the end of the $2 \mathrm{~h}$ period, the intruder was removed, and the residents were left undisturbed until the following day when the protocol was repeated. Different intruders were used on consecutive nights. The health status of the mice was carefully examined throughout the experiment. Mice that were injured or moribund were removed from the study. Consistent with previous studies using RSD (Engler et al., 2004), <5\% of mice met the early removal criteria. Control (CON) mice were left undisturbed in their home cages.

Minocycline treatment. Minocycline (Sigma-Aldrich) was administered in vivarium drinking water. Solutions were prepared fresh daily and administered in opaque sipper bottles. Mice and water bottles were weighed daily to adjust dosage to $90 \mathrm{mg} / \mathrm{kg}$. Oral minocycline treatment was started 1 day before the beginning of RSD and was terminated on the last day of RSD.

RNA isolation and real-time PCR. RNA was isolated from the hippocampus using the Tri-reagent/isopropanol precipitation protocol. RNA concentration was determined by spectrophotometry (Eppendorf). RT was performed using a High-Capacity cDNA Reverse Transcription Kit (Applied Biosystems). Real-time PCR was performed using the Applied Biosystems Taqman Gene Expression Assay-on-Demand Gene Expression protocol. In brief, target cDNA [IL-1 $\beta$, TNF $\alpha$, IL-6, arginase-1, brain-derived neurotrophic factor (BDNF), vascular endothelial growth factor (VEGF), nerve growth factor (NGF), and insulin-like growth factor-1 (IGF-1)] and reference cDNA [glyceraldehyde-3-phosphate dehydrogenase (GAPDH)] were amplified simultaneously using a primer/probe set for each gene of interest (Life Technologies). Fluorescence was determined on an ABI PRISM 7300sequence detection system (Applied Biosystems). Data were analyzed using the comparative threshold cycle method, and results were expressed as fold difference from GAPDH.

Immunohistochemistry and digital imaging analysis for Iba-1 and CD45. Brain samples were collected after transcardial perfusion with sterile PBS, $\mathrm{pH}$ 7.4 , followed by $4 \%$ formaldehyde. Brains were postfixed in $4 \%$ formaldehyde for $24 \mathrm{~h}$ and then in $30 \%$ sucrose for another $48 \mathrm{~h}$. Fixed brains were frozen with isopentane $\left(-78^{\circ} \mathrm{C}\right)$ and sectioned $(30 \mu \mathrm{m})$ using a Microm HM550 cryostat. Brain regions within the hippocampus were identified by reference markers in accordance with the stereotaxic mouse brain atlas (Paxinos and Franklin, 2008). To label for Iba-1 or CD45, sections were placed free-floating in cryoprotectant until staining. Next, sections were washed in PBS and then blocked (5\% normal goat serum, $1 \%$ BSA, and $0.5 \%$ Triton X-100 in PBS) and incubated with rabbit anti-mouse Iba-1 (1:1000; Wako Chemicals) or rat anti-mouse CD45 (1:500; Abcam) overnight at $4^{\circ} \mathrm{C}$. Then sections were washed in PBS and incubated with a fluorochromeconjugated secondary antibody (Alexa Fluor 488 or Alexa Fluor 594). Sections were mounted on slides, coverslipped with Fluoromount G (Beckman Coulter), and stored at $-20^{\circ} \mathrm{C}$. For each mouse, five to six representative images were taken at $20 \times$ magnification from the dentate gyrus (DG) of the hippocampus. Fluorescent images were taken with a Zeiss 510 Meta confocal microscope and analyzed using NIH ImageJ software. For CD45, cells with positive labeling were counted in each hippocampal section. Iba-1 labeling 
was analyzed using a digital image analysis system (Donnelly et al., 2009). In brief, a threshold for positive labeling was determined for each image that included all cell bodies and processes but excluded background staining. Data were processed by densitometric scanning of the threshold targets using NIH ImageJ software. Proportional area was reported as the average percentage area in the positive threshold for all representative images (Wohleb et al., 2013).

Spatial memory in the Morris water maze. Spatial memory (Morris, 1984) was determined using a modified version of the classic Morris water maze (MWM; Morris, 1981). The apparatus consisted of a white 180-cm-diameter tub filled with a mixture of water and white paint (at room temperature). A clear plastic platform (12 cm diameter) was concealed $1 \mathrm{~cm}$ beneath the surface of the water and was placed in a position $20 \mathrm{~cm}$ away from the edge of the tub. The area surrounding the apparatus consisted of two distinct extramaze geometric cues and additional spatial cues inherent to the room. The experimenter and recording equipment were concealed behind a curtain during testing. The spatial memory assay involved a $5 \mathrm{~d}$ acquisition phase after RSD and a probe trial on day 6. Acquisition consisted of four trials per day, with the platform in the same position throughout the task. A 30 min intertrial interval was used throughout the acquisition phase. Maximum trial duration was $60 \mathrm{~s}$. If the platform was not reached within $60 \mathrm{~s}$, then the mouse was placed on the platform and a latency of $60 \mathrm{~s}$ was recorded. Mice were placed at one of four positions in a quasi-random balanced order. Latency and total distance to reach the platform and percentage time in the outer annulus of the tub were recorded. During the probe trial on day 6 , the platform was removed, and total distance traveled and percentage time in each quadrant were recorded for $60 \mathrm{~s}$. Behavior was recorded and analyzed using the Noldus EthoVision XT 8.0 Software.

Working memory in the MWM. Working memory was determined in an adaptation of the MWM as was described previously (Sparkman et al., 2006). All conditions were the same as described above unless noted otherwise. There were three massed trials per day with an intertrial interval of $30 \mathrm{~s}$ and maximum trial duration of $120 \mathrm{~s}$. Each trial lasted until the platform was reached or until the maximum trial duration elapsed. If the platform was not reached within $120 \mathrm{~s}$, then the mouse was placed on the platform and a score of $120 \mathrm{~s}$ was recorded. In a pseudorandom and experimentally balanced manner, mice were placed in one of four quadrants $\sim 3 \mathrm{~cm}$ from the edge of the tub. The location of the platform was changed every day but remained in the same place during trials on the same day. Average velocity, latency to platform, distance to platform, and duration spent in the outer annulus were recorded and analyzed using the Noldus EthoVision XT 8.0 Software.

Spatial memory in the Barnes maze. Hippocampal-dependent learning and memory recall were determined using a previously described Barnes maze paradigm with some modifications (Bach et al., 1995). The acclimation phase consisted of two trials: (1) mice were guided to the escape hole and allowed $2 \mathrm{~min}$ in the escape box; and (2), mice were guided to an incorrect or "dummy" hole and then guided to the escape hole and allowed $2 \mathrm{~min}$ in the escape hole. Trials were initiated $30 \mathrm{~min}$ apart for each mouse. After the acclimation day, the position of the escape box was shifted to its permanent location for the remainder of the paradigm for mice to learn overt stationary spatial cues to find the escape box. The acquisition phase consisted of four trials per day for 4 consecutive days. Mice were placed in the center of the maze under a semi-opaque container for $15 \mathrm{~s}$. The trial recording began with the removal of the container. Each trial lasted $120 \mathrm{~s}$ or until the mouse entered the escape hole. If the mouse did not reach the escape hole in the allotted time, then it was guided to the hole. Speed, distance traveled, time to locate the escape hole, and the number of errors were determined. To evaluate immediate memory recall, mice were reexposed to the Barnes maze trial 24 and $48 \mathrm{~h}$ after RSD. For long-term memory recall, reexposure was performed on days 28 and 29 after RSD. Reexposure consisted of one $60 \mathrm{~s}$ trial during which the speed, distance, time to locate the escape hole, and the number of errors were determined. Mice in the acquisition phase and recall trial were tracked, recorded, and analyzed using the Noldus EthoVision XT 8.0 Software.

5'Bromodeoxyuridine and doublecortin labeling. The proliferation of cells in the DG was determined using 5'bromodeoxyuridine (BrdU) labeling. BrdU (10 mg/ml; Sigma-Aldrich) was dissolved in warm PBS and then filtered. On the last 3 nights of RSD (i.e., cycles 4, 5, and 6), mice were injected with $50 \mathrm{mg} / \mathrm{kg}$ BrdU at 4:00 P.M. (1 h before social defeat). Brains were collected for BrdU immunohistochemistry $14 \mathrm{~h}(0.5 \mathrm{~d}), 10 \mathrm{~d}$, or $28 \mathrm{~d}$ after the last injection of BrdU. For quantification of BrdUpositive $\left(\mathrm{BrdU}^{+}\right)$and doublecortin-positive $\left(\mathrm{DCX}^{+}\right)$cells, every sixth section throughout the hippocampus was collected. For BrdU labeling, sections were washed, denatured in $2 \mathrm{~N} \mathrm{HCl}$ at $37^{\circ} \mathrm{C}$ for $30 \mathrm{~min}$, and blocked (1\% BSA/PBS, $5 \%$ NGS, and $0.1 \%$ Triton X-100). Sections were then incubated in primary antibody (mAb, 1:1000, rat anti-BrdU; AbD Serotec) at $4^{\circ} \mathrm{C}$ for $24 \mathrm{~h}$ and then secondary antibody (Alexa Fluor 488) at room temperature for $1 \mathrm{~h}$. For DCX labeling, sections were washed, blocked (1\% BSA/PBS, 5\% donkey serum, and 0.5\% Triton X-100) for $1 \mathrm{~h}$ and then incubated in primary antibody ( $\mathrm{mAb}, 1: 200$, goat anti-DCX; Santa Cruz Biotechnology) at $4^{\circ} \mathrm{C}$ for $48 \mathrm{~h}$, followed by secondary antibody (Alexa Fluor 594) at $4^{\circ} \mathrm{C}$ overnight. Sections were mounted on slides, coverslipped with Fluoromount G (Beckman Coulter), and stored at $-20^{\circ} \mathrm{C}$. Fluorescent images were visualized using a Zeiss 510 Meta confocal microscope, captured, and then analyzed using MetaMorph software. The total number of $\mathrm{BrdU}^{+}$cells and $\mathrm{DCX}^{+}$cells in the DG were extrapolated for the entire volume of the hippocampus. A previous study was used as a reference for morphological comparison of immature and mature $\mathrm{DCX}^{+}$neurons (Zhao et al., 2006).

Fate mapping of $\mathrm{BrdU}^{+}$cells. For phenotypic analysis of $\mathrm{BrdU}^{+}$cells at 10 and $28 \mathrm{~d}$ after injection, double labeling was performed with rat antiBrdU (mAb, 1:1000; AbD Serotec), goat anti-DCX (1:500; Abcam), and rabbit anti-NeuN (1:1000; Abcam) or rabbit anti-GFAP (rabbit, 1:1000; Dako). Sections were collected at 10 and $28 \mathrm{~d}$ after injection of BrdU. Fluorescent samples were visualized using an epifluorescent Leica DM5000B microscope. Images were captured on the Leica DFC300 FX camera and then analyzed using NIH ImageJ software. The total number of cells with positive labeling in the hippocampus was counted and represented per brain section.

Social interaction. Social avoidance was determined as described previously (Berton et al., 2006; Krishnan et al., 2007; Wohleb et al., 2014a). In Trial 1 (empty), an experimental mouse was placed into the arena with an empty wire mesh cage, and activity was recorded for $2.5 \mathrm{~min}$. In Trial 2 (social), an unfamiliar CD-1 mouse was placed in the wire mesh cage, the experimental mouse was placed in the arena, and activity was recorded for $2.5 \mathrm{~min}$. Activity in the social avoidance behavior test was video recorded and analyzed using Noldus EthoVision XT Software.

Statistical analyses. Observations 2 SDs above and below the mean were counted as outliers and were excluded in the subsequent analyses. To determine significant main effects and interactions between main factors, data were analyzed using one-way, two-way, or repeatedmeasures ANOVA using the general linear model procedures of SPSS statistical software (IBM). Specifically, Barnes maze and MWM data were averaged across trials on the same day. Data with repeated trials were tested for sphericity using Mauchly's test and were then analyzed with repeated-measures ANOVA to determine the effect of day, trial, or experimental condition. In the event of a main effect of experimental treatment, differences between group means were evaluated by an $F$-protected $t$ test. Post hoc analyses are presented graphically in the figures. All data are expressed as treatment means \pm SEMs.

\section{Results}

Increased inflammation and presence of $\mathrm{CD} 45^{+}$myeloid cells in the hippocampus after RSD

It has been reported previously that RSD activated microglia and promoted monocyte trafficking to the brain (Wohleb et al., 2013). Moreover, these events contributed to an enhanced inflammatory profile, activated IL-1 signaling in the brain, and affected the development of prolonged anxiety-like behavior. Stress-induced monocyte trafficking and inflammatory signaling was localized within the limbic system (including the hippocampus). This is relevant because the hippocampus is critical in neuroplasticity, behavior, and cognition (McEwen, 1999). Therefore, the objective of this study was to determine the effects of RSD on hippocampal-dependent memory and neuronal plasticity. 
A

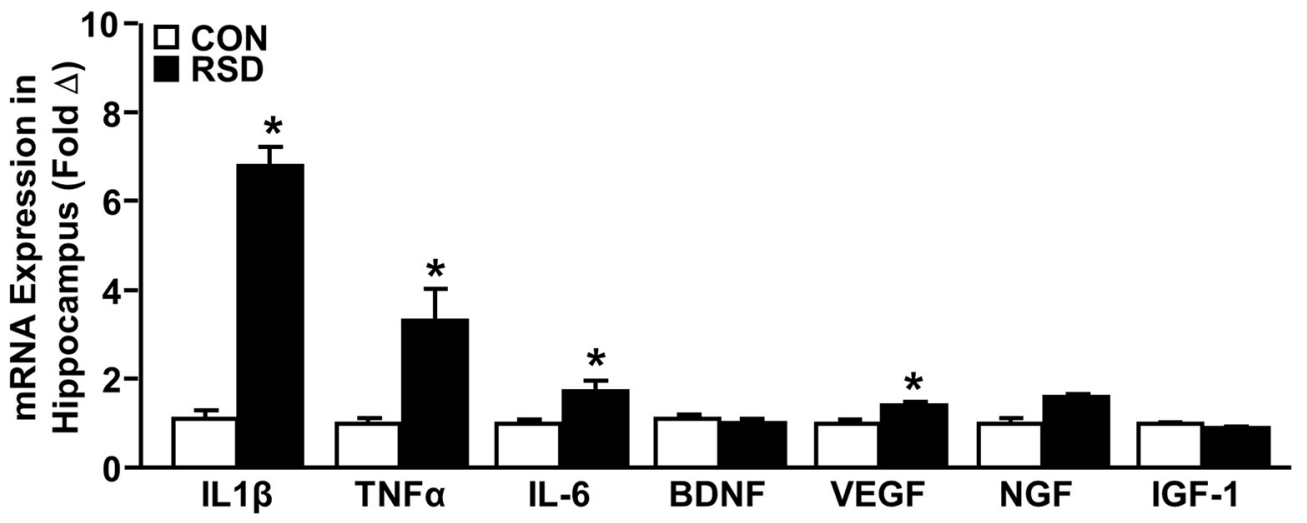

B

$\operatorname{CON}(0.5 d)$
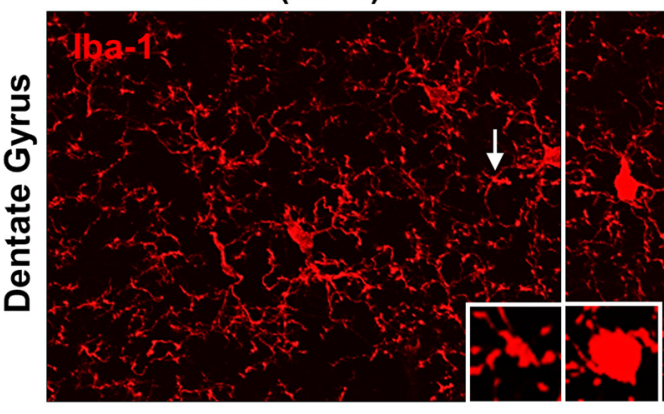

D



RSD (0.5 d)

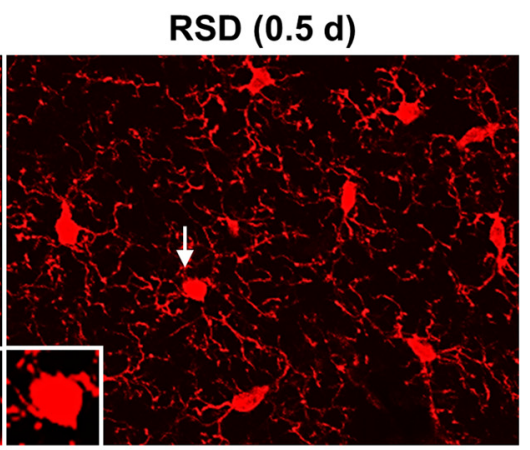

C

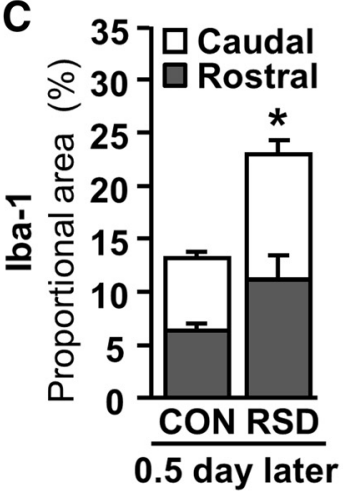

E

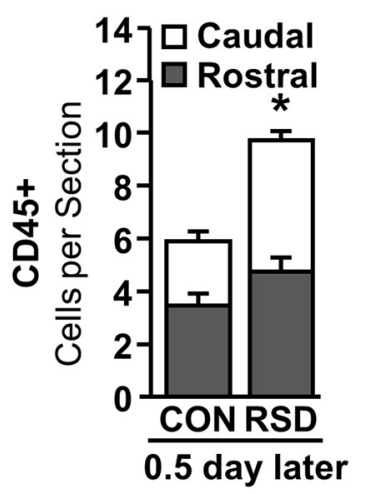

Figure 1. Increased inflammation and presence of $\mathrm{CD} 45^{+}$myeloid cells in the hippocampus after RSD. Mice were subjected to six cycles of RSD or left undisturbed as CONs. $A$, The mRNA levels of several inflammatory mediators (IL-1 $\beta$, TNF, IL-6, and arginase) and growth factors (BDNF, VEGF, NGF, and IGF-1) were determined in the hippocampus collected immediately after RSD ( $n=6$ ). In a related experiment, mice were subjected to six cycles of social defeat, and mice were perfused and fixed with $4 \%$ paraformaldehyde $14 \mathrm{~h}$ later. Brain samples were postfixed, frozen, and sectioned, and Iba-1 or CD45 expression was determined $(n=6) . \boldsymbol{B}$, Representative images of Iba- 1 labeling are shown in the DG. The arrows show the Iba- $1^{+}$cell depicted in the inset. $C$, Quantification of Iba-1 labeling for the entire volume of the hippocampus with rostral-caudal distinction. $\boldsymbol{D}$, Representative images of CD45 labeling are shown in the DG. The arrows show the CD45 ${ }^{+}$cell depicted in the inset. $E$, Quantification of $\mathrm{CD} 5^{+}$cells per hippocampal section. Data represent mean \pm SEM. ${ }^{*} p<0.05$, means are significantly different from CON.

In the first experiment, mice were exposed to six cycles of social defeat, and mRNA expression of several inflammatory mediators and growth factors were determined in the hippocampus immediately after the last cycle. Fig. $1 A$ shows that RSD increased mRNA expression of IL-1 $\beta(p<0.0001)$, IL-6 ( $p<0.05)$, and TNF $\alpha(p<$ $0.05)$ in the hippocampus immediately after RSD. These data are consistent with our previous findings (Wohleb et al., 2013). In addition, mRNA expression of NGF $(p<0.05)$ and VEGF $(p<0.01)$ were also increased in the hippocampus immediately after RSD. The expression of genes coding for BDNF and IGF-1 were unaffected by RSD.

Next, microglial Iba-1 immunoreactivity and the presence of $\mathrm{CD}_{4}{ }^{+}$monocytes were assessed in the DG of the hippocampus.
Figure $1 B$ shows representative images of Iba- 1 labeling of microglia in the DG. RSD promoted changes in microglial morphology marked by larger soma size and shorter, thicker processes. These morphological changes, associated with an inflammatory profile, resulted in an overall increase in Iba-1 proportional area across the caudal and rostral DG $\left(F_{(1,19)}=11.66, p<0.05\right.$; Fig. $\left.1 C\right)$ that was significantly augmented in the caudal hippocampus compared with the rostral hippocampus after RSD $(p<0.05)$. Figure $1 D$ shows representative images of $\mathrm{CD} 45^{+}$monocytes in the DG of CON and RSD mice. There was a significant increase in the number of CD $45^{+}$ cells in the caudal and rostral DG after $\operatorname{RSD}\left(F_{(1,20)}=4.76, p<0.05\right.$; Fig. $1 E$ ). Additional differentiation of the DG into caudal and rostral regions showed that the increase of $\mathrm{CD} 45^{+}$monocytes with RSD 
was more pronounced in the caudal hippocampus $(p<0.05)$ of the RSD mice. Overall, these data indicated that RSD elevated proinflammatory cytokine levels in the whole hippocampus and increased microglial Iba-1 immunoreactivity and number of $\mathrm{CD}_{4} 5^{+}$monocytes that was more pronounced in the caudal hippocampus.

Impaired performance on the working memory version of the MWM was related to thigmotaxis

Prolonged exposure to inflammatory cytokines may negatively affect hippocampaldependent spatial memory (Sparkman et al., 2006; Hein et al., 2010). To test this idea in RSD, mice were exposed to six cycles of social defeat, and working memory was assessed for $5 \mathrm{~d}$ using an adapted version of the MWM (Fig. 2A). In this design, mice were trained to locate the hidden platform that changed location on each day of testing (Fig. $2 B$ ). Figure $2 C$ shows the representative search patterns of CON and RSD mice on day 3 of testing in the MWM. RSD did not affect swim velocity during the $5 \mathrm{~d}$ of testing $\left(F_{(1,22)}=0.71, p=0.794\right.$; Fig. $\left.2 D\right)$. A repeated-measures ANOVA revealed that RSD did not significantly affect performance across all $5 \mathrm{~d}$ on either latency $\left(F_{(1,22)}=\right.$ 1.02, $p=0.331$; Fig. $2 E)$ or distance $\left(F_{(1,22)}=1.00, p=0.335\right.$; Fig. $\left.2 F\right)$. However, there was a significant main effect of stress when analyzed across the first $3 \mathrm{~d}$ on both latency $\left(F_{(1,22)}=5.82, p<0.05\right)$ and distance $\left(F_{(1,22)}=5.21, p<0.05\right)$. Post hoc analysis indicated that RSD tended to increase latency and distance to reach the platform on each of the first 3 testing (D7-D9) days ( $p \leq 0.1$ for each; Fig. $2 E, F)$. By days 4 and 5 of testing (D10-D11), latency and distance traveled were no longer affected by RSD. In addition, there was significant increase in performance across days on both latency $\left(F_{(4,19)}=23.66, p<0.001\right)$ and distance $\left(F_{(4,19)}=16.87, p<0.001\right)$ to reach the platform independent of stress condition. This temporal pattern is indicative of learning. It is important to note that there was a main effect of RSD on time spent in the outer annulus of the maze $\left(F_{(1,22)}=9.25, p<0.01\right.$; Fig. $\left.2 G\right)$. Post hoc analysis confirmed that RSD mice spent more time in the outer annulus on D7-D9 compared with CON mice ( $p<0.05$ for all $3 \mathrm{~d}$ ). This search strategy resembles an anxiety-like thigmotactic behavior, and it was readily apparent in the representative search paths in Figure $2 C$. This altered anxiety-like search strategy may explain the increased time and distance to reach the escape platform observed after RSD. Consistent with this, there was a significant correlation between the average percentage time in the outer annulus and average latency $(r=0.632, p<0.001)$ and average distance $(r=0.638$, $p<0.001)$ across the first 3 testing days. Moreover, thigmotaxis is a significant covariate between stress and latency $\left(F_{(1,22)}=6.75, p<\right.$ $0.05)$ and stress and distance $\left(F_{(1,22)}=7.11, p<0.05\right)$ on the first $3 \mathrm{~d}$.
A Working Memory Assessment in the MWM

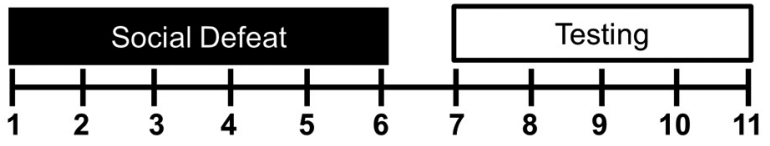

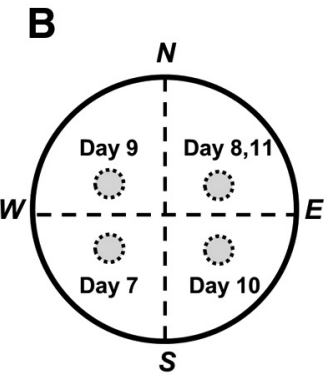
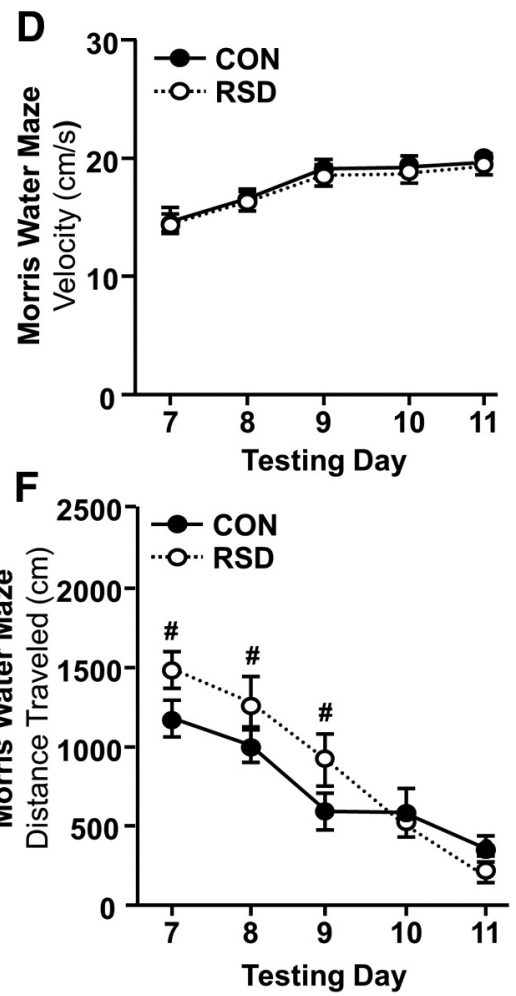
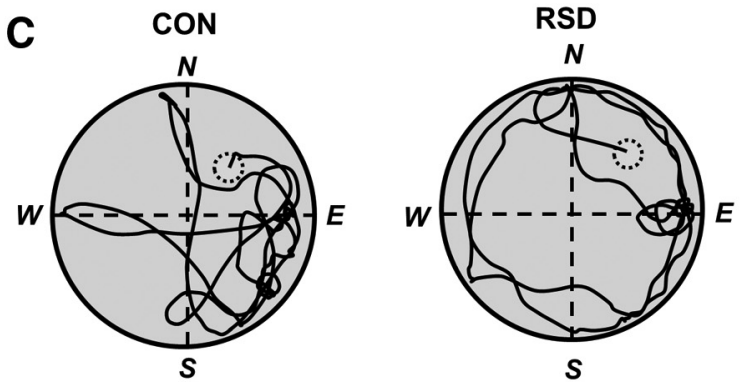

E
G

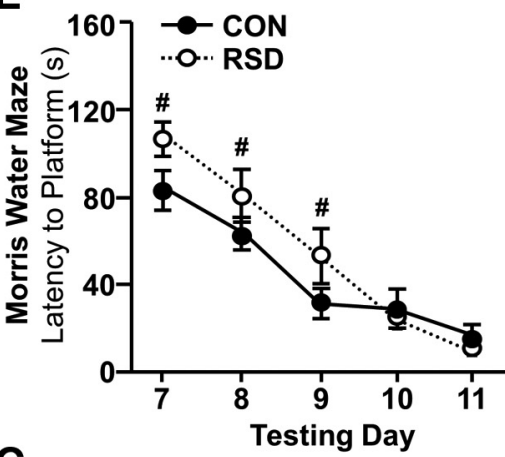

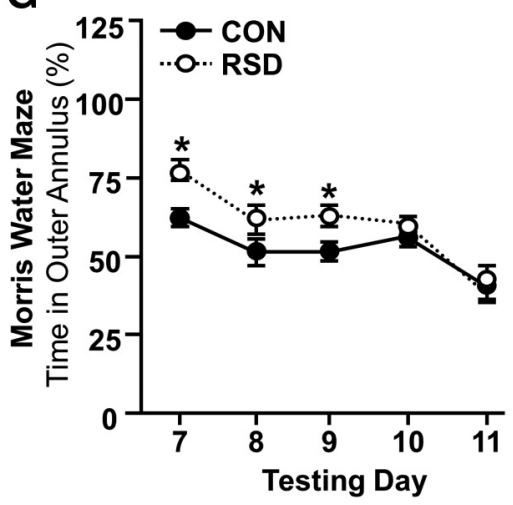

Figure 2. Impaired working memory after RSD. A, Representative time line of working memory assessment in the MWM. Mice were subjected to six cycles of RSD or left undisturbed as CONs. Working memory was examined for $5 \mathrm{~d}$ (D7-D11) after completion of RSD $(n=10)$. $\boldsymbol{B}$, In this paradigm, the escape platform was moved to a different quadrant each testing day. $\boldsymbol{C}$, Representative paths for CON and RSD mice in the MWM on day 3. Velocity $(\boldsymbol{D})$, latency to the platform $(\boldsymbol{E})$, distance traveled $(\boldsymbol{F})$, and percentage time in the outer annulus $(\boldsymbol{G})$ were determined for all 5 testing days. Graphs represent the mean \pm SEM. ${ }^{*} p<0.05$, means are significantly different from CONs; ${ }^{\#} p=0.06-0.10$, means tended to be different from CONs.

When thigmotaxis is controlled for as a covariate, the effect of RSD on latency $\left(F_{(1,22)}=7.22, p=0.405\right)$ and distance $\left(F_{(1,22)}=6.46, p=\right.$ $0.531)$ is no longer apparent. Together, RSD caused a modest and transient impairment in performance on this working memory version of the MWM that was likely attributable to an anxiety-like or thigmotactic search strategy.

\section{RSD impaired spatial memory recall but not acquisition in} the MWM

To further assess cognitive functioning, learning and spatial memory recall were examined using another variation of the MWM (Fig. 3A). In this experiment, mice were trained on the MWM to acquire the location of the hidden platform on the first $5 \mathrm{~d}$ (acquisition phase, D7-D11) after the six cycles of RSD 


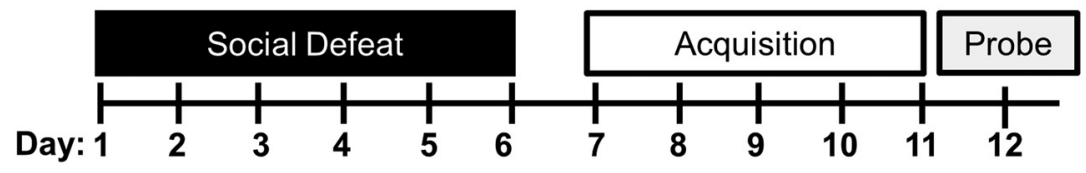

B

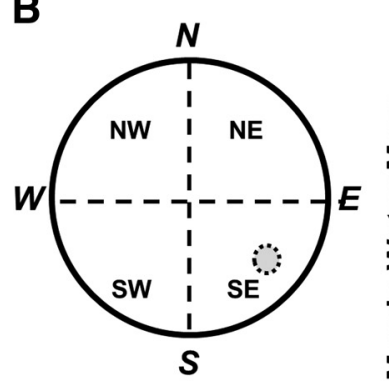

C

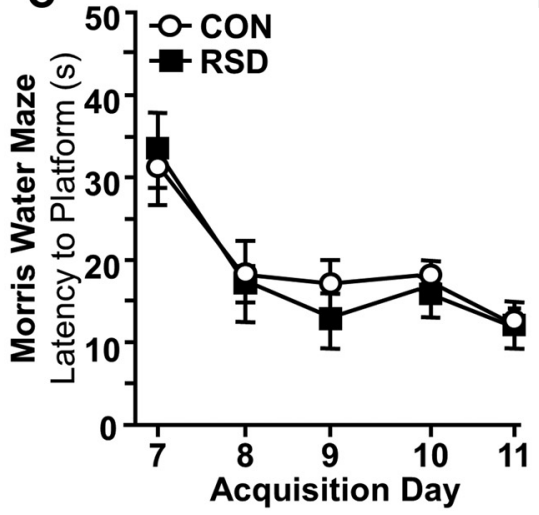

D

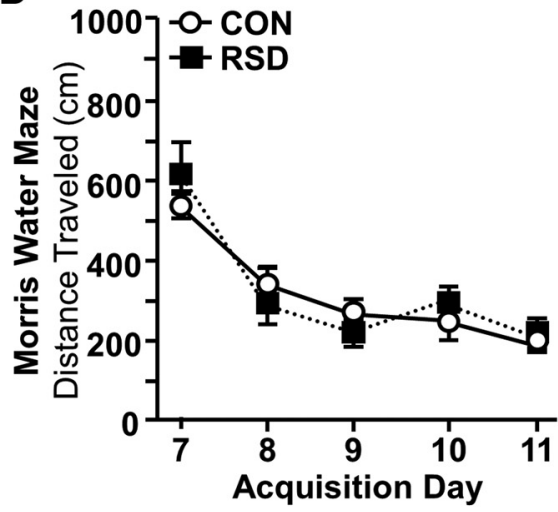

E

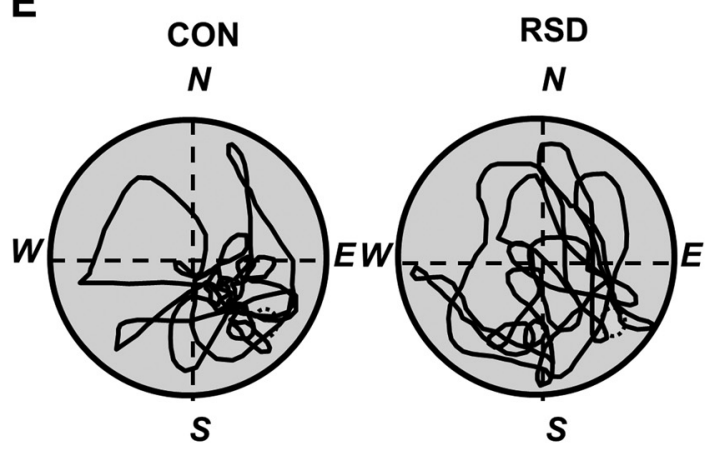

F

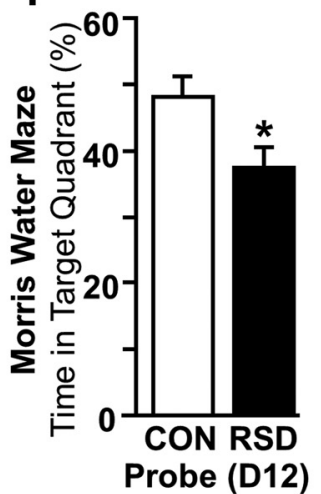

G

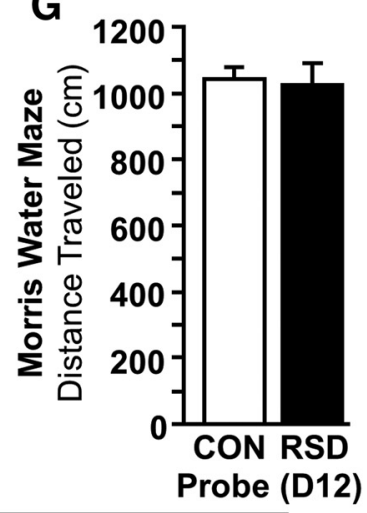

6 days after RSD

Figure 3. Impaired spatial memory recall in the MWM after RSD. A, Representative time line of learning and memory recall assessments in the MWM. Mice were subjected to six cycles of RSD or left undisturbed as CONs. Learning was examined after the completion of RSD for $5 \mathrm{~d}(\mathrm{D} 7-D 11)$, and then memory recall was tested (D12; $n=8)$. $\boldsymbol{B}$, In this paradigm, the escape platform remained in the same location each testing day of the acquisition phase but was removed during the probe trial. During the acquisition phase, latency to the platform $(\boldsymbol{C})$ and distance traveled $(\boldsymbol{D})$ were determined each of the $5 \mathrm{~d}$ of testing. $\boldsymbol{E}$, Representative search paths of CON and RSD mice during the probe trial (D12). Spatial memory recall was assessed during the probe trial, and distance traveled $(\boldsymbol{F})$ and percentage of time in the target quadrant $(\boldsymbol{G})$ were determined. Graphs and bars represent the mean \pm SEM. ${ }^{*} p<0.05$, means are significantly different from CONs.

(Fig. 3B). Then, memory recall was probed by removing the hidden platform on day 6 after RSD (D12). During the $5 \mathrm{~d}$ of acquisition, performance was not significantly affected by stress on either latency $\left(F_{(1,24)}=1.264, p=0.273\right.$; Fig. $\left.3 C\right)$ or distance $\left(F_{(1,24)}=0.156, p=0.697\right.$; Fig. $\left.3 D\right)$ to reach the escape platform. In addition, regardless of stress treatment, performance on the MWM significantly improved across acquisition days on latency to the platform $\left(F_{(4,21)}=19.12, p<0.001\right.$; Fig. $\left.3 C\right)$ and distance traveled $\left(F_{(4,21)}=24.68, p<0.001\right.$; Fig. $\left.3 D\right)$. This observation confirmed that both groups learned the location of the platform during the acquisition phase. However, during the probe trial, CON mice outperformed the RSD mice in memory recall. Representative paths from the probe trial are shown for CON and RSD mice in Figure $3 E$. Mice exposed to RSD spent significantly less time in the target quadrant compared with CON mice $(p<$ 0.05; Fig. $3 F$ ) during the probe trial (D12). Reduced time in the target quadrant during the probe trial was not attributable to alterations in total distance traveled ( $p=0.811$; Fig. $3 G)$. Collec- tively, these results demonstrate impaired spatial memory recall in mice exposed to RSD.

Impaired spatial memory recall in the Barnes maze after RSD was not associated with anxiety, impaired encoding, or deficient memory consolidation

Because RSD-induced anxiety-like behavior persists for at least $8 \mathrm{~d}$ (Wohleb et al., 2014a), it is possible that decreased time spent in the target quadrant of the MWM was attributable to increased anxiety-like behavior. Moreover, because mice were trained on the maze after exposure to RSD, the apparent impairment in spatial memory may be indicative of deficient encoding rather than impaired recall. To circumvent the possible anxiety- or encoding-related deficits, spatial memory recall was assessed in the Barnes maze. In this design, mice were allowed to learn the location of the escape hole for $4 \mathrm{~d}$ before the beginning of RSD. Next, mice were exposed to RSD for $6 \mathrm{~d}$, and memory recall was 
Memory Recall Assessment in the Barnes Maze

Day: -3

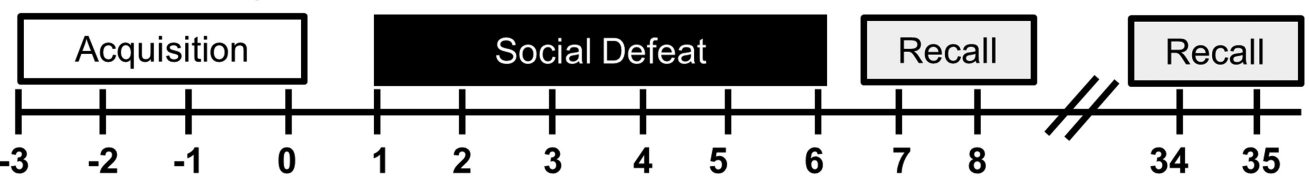

B

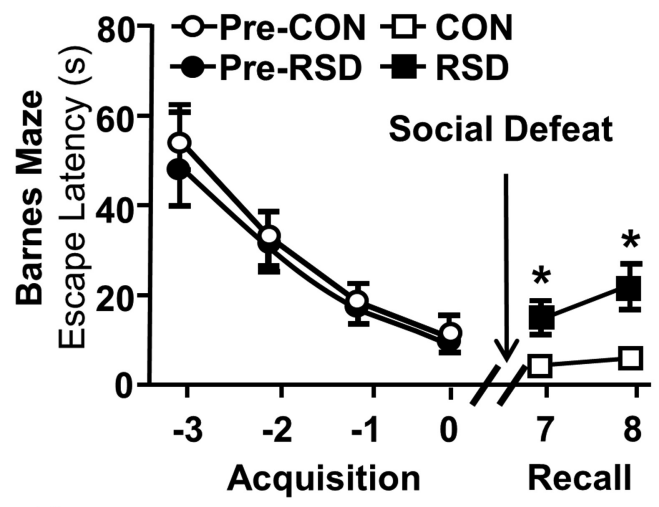

D
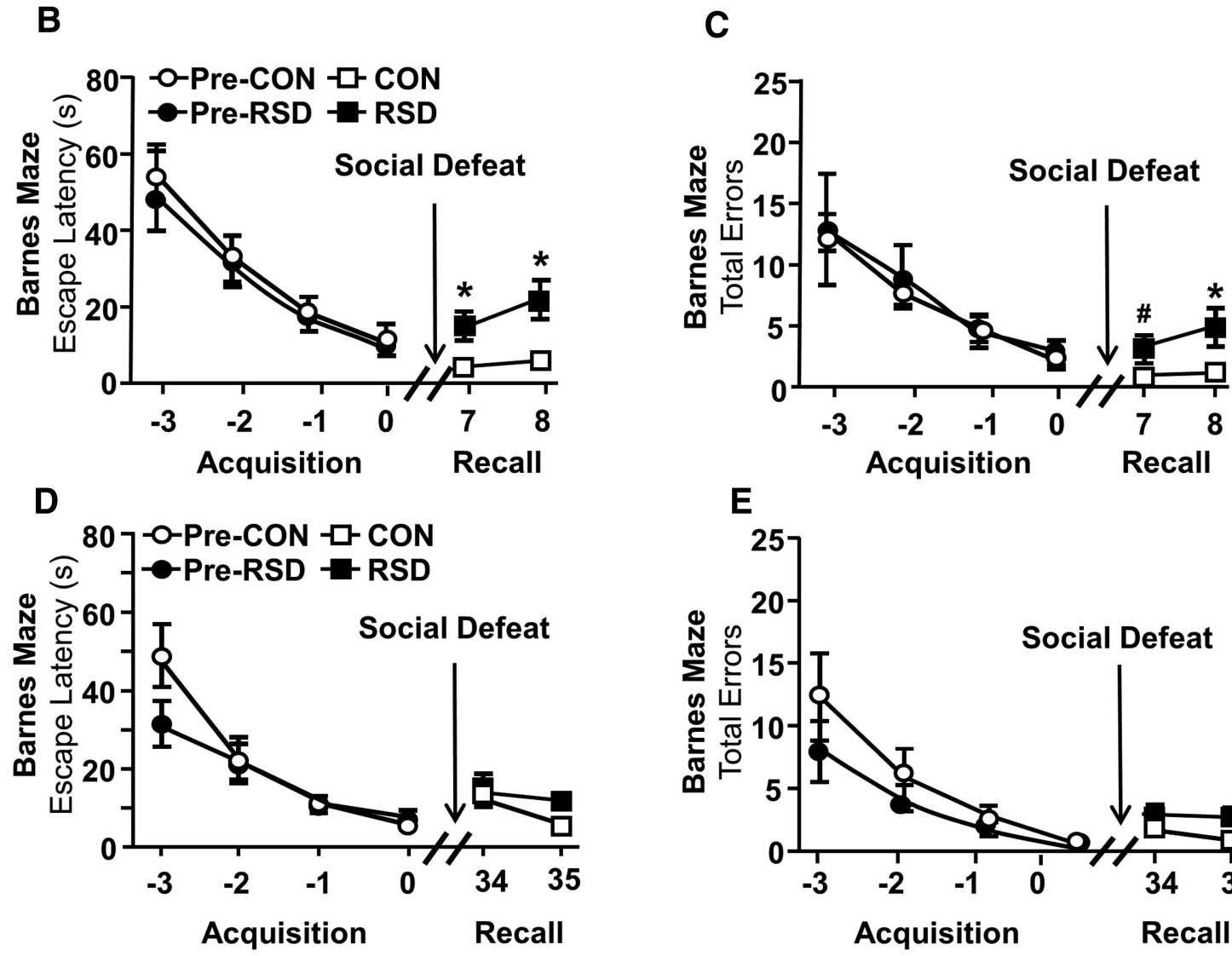

E

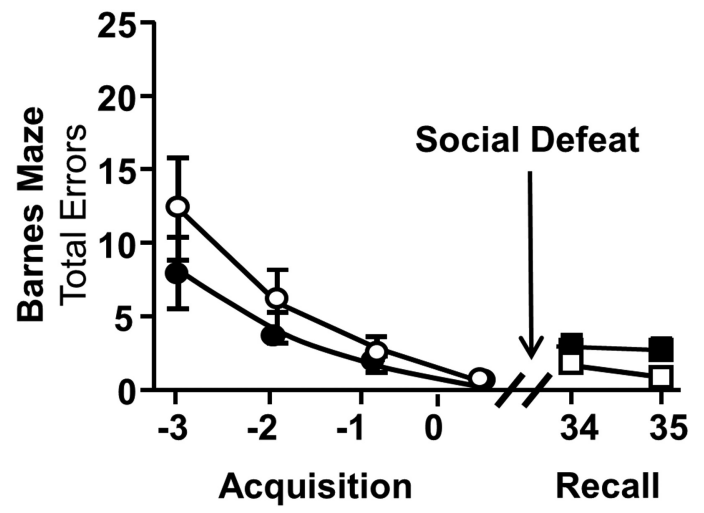

Figure 4. Impaired spatial memory recall in the Barnes maze after RSD. A, Representative time line of cognitive assessment in the Barnes maze after RSD. Mice were trained on the Barnes maze to acquire learning before social defeat (Pre-Con and Pre-RSD). Next, mice were subjected to six cycles of RSD or left undisturbed as CONs, and memory recall was determined on D7 and D8. Escape latency $(\boldsymbol{B})$ and total errors $(\boldsymbol{C})$ are shown before and after RSD exposure. In a related experiment, mice were used as above, and memory recall was determined at 34 and $35 \mathrm{~d}$. Escape latency $(\boldsymbol{D})$ and total errors $(\boldsymbol{E})$ are shown before and after RSD exposure. Lines represent the mean \pm SEM. ${ }^{*} p<0.05$, means are significantly different from CONs; ${ }^{\#} p=0.06-0.10$, means tended to be different from CONs.

tested for $2 \mathrm{~d}$ either immediately after RSD (D7 and D8) or $28 \mathrm{~d}$ later (D34 and D35; Fig. 4A).

There were no differences between the groups in escape latency $\left(F_{(1,17)}=0.005, p=0.946\right.$; Fig. $\left.4 B\right)$ or number of errors $\left(F_{(1,17)}=0.115, p=0.739\right.$; Fig. $\left.4 C\right)$ during acquisition before RSD (pre-CON and pre-RSD). In addition, mice exhibited a daydependent learning effect on both latency $\left(F_{(3,15)}=19.72, p<\right.$ $0.001)$ and errors $\left(F_{(3,15)}=9.63, p<0.001\right)$ to find the platform during the acquisition phase. Memory recall was then assessed for 2 consecutive days after the sixth cycle of social defeat (D7 and D8). Across both days, RSD mice showed increased latency to find the escape hole $\left(F_{(1,17)}=10.82, p<0.005\right.$; Fig. $\left.4 B\right)$ when compared with the CON mice ( $p<0.05$; for each day). RSD also increased the number of errors $\left(F_{(1,17)}=5.96, p<0.05\right.$; Fig. $\left.4 C\right)$ to reach the escape hole on D7 $(p<0.1)$ and D8 $(p<0.05)$. There were no significant day $X$ stress interactions on either latency $\left(F_{(1,17)}=0.885, p<0.361\right)$ or errors $\left(F_{(1,17)}=0.588, p<\right.$ 0.454 ) during the testing phase (D7 and D8). Together, these data indicate that RSD disrupts short-term memory recall in the Barnes maze.

Next, a similar paradigm was used to test performance in the Barnes maze $28 \mathrm{~d}$ after RSD. Mice were allowed to acquire the location of the escape platform for 4 days before RSD. Again, the CON and RSD mice showed no differences in escape latency $\left(F_{(1,23)}=0.172, p=0.683\right.$; Fig. $\left.4 D\right)$ or the number of errors during the acquisition phase $\left(F_{(1,23)}=0.172, p=\right.$ 0.683; Fig. $4 E)$. In addition, mice exhibited a day-dependent learning effect on both latency $\left(F_{(3,21)}=42.87, p<0.001\right)$ and errors $\left(F_{(3,21)}=18.75, p<0.001\right)$ to find the platform during the acquisition phase. Twenty-eight days after the completion of RSD, memory recall was assessed at two time points (D34 and D35). No detectable differences were observed in escape latency $\left(F_{(1,23)}=0.589, p<0.453\right.$; Fig. $\left.4 D\right)$ or the number of errors $\left(F_{(1,23)}=0.219, p<0.645\right.$; Fig. $\left.4 E\right)$ between the CON and RSD mice. It is important to note that all mice retained a strong memory of the location of the escape hole even $28 \mathrm{~d}$ 
A

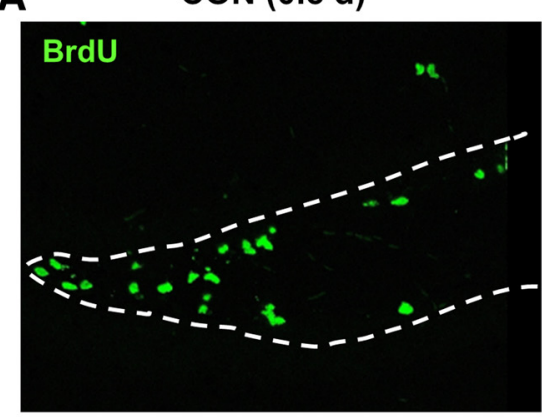

C

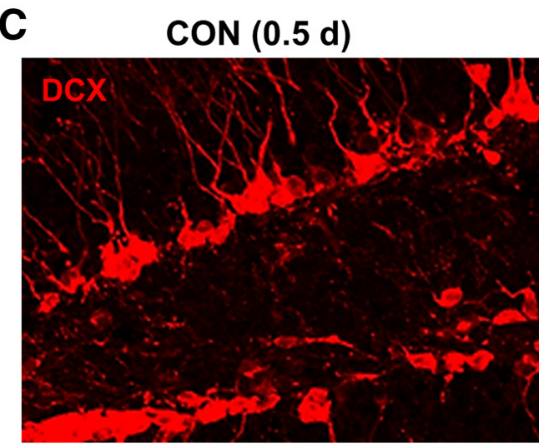

$\operatorname{RSD}(0.5 \mathrm{~d})$

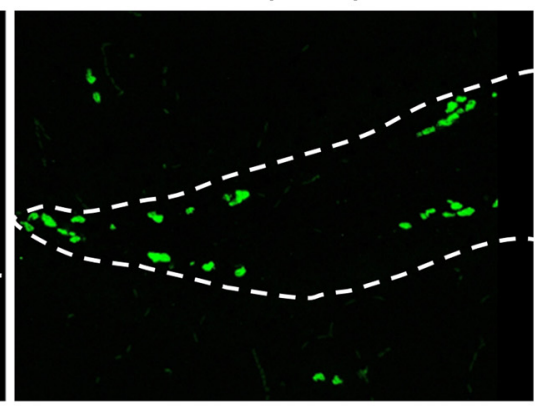

$\operatorname{RSD}(0.5 \mathrm{~d})$

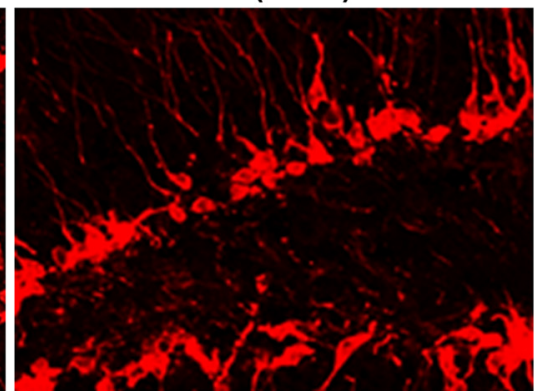

B

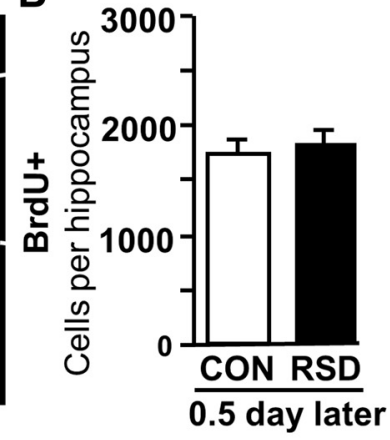

E

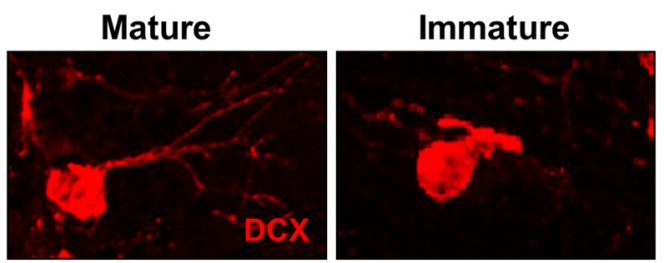

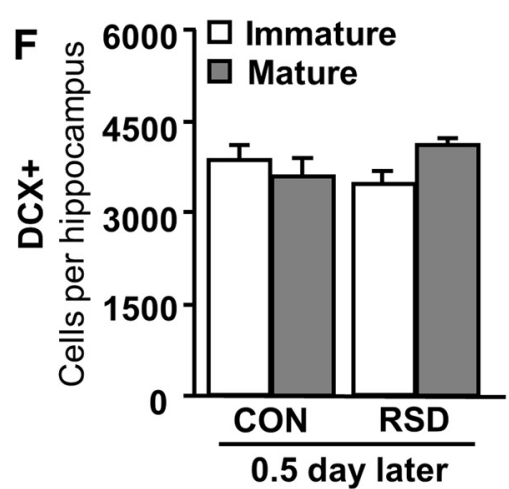

Figure 5. Number of proliferating progenitor cells and young neurons in the hippocampus remain unchanged $0.5 \mathrm{~d}$ after RSD. Mice were subjected to six cycles of RSD or left undisturbed as CONs. BrdU was injected during the last three cycles of social defeat. BrdU ${ }^{+}$and $D C X^{+}$cells were determined in the $D G 0.5$ d later $(n=6)$. $A$, Representative images of BrdU labeling in the DG for CON and RSD mice. B, Quantification of BrdU labeling in the DG for the entire volume of the hippocampus. C, Representative images of $D C X^{+}$neurons in the DG for CON and RSD mice. $D, Q$ Quantification of DCX labeling in the $D G$ for the entire volume of the hippocampus. $\boldsymbol{E}$, Representative images of mature and immature $D C X^{+}$neurons. $F$, Quantification of immature $D C X$ labeling and mature $D C X$ labeling. Bars represent the mean \pm SEM.

after learning. For instance, performance was improved significantly on D34 and D35 compared with D1 on both latency and distance ( $p<0.001$ for all). Collectively, these data indicate that RSD caused transient deficits in spatial memory recall in the Barnes maze that were not associated with anxiety-like search strategies, impaired encoding, or deficient consolidation.

The number of proliferating progenitor cells and young neurons in the hippocampus was unchanged $0.5 \mathrm{~d}$ after RSD Cognitive impairments after stress have been associated with inflammation and impaired neurogenesis (Ben MenachemZidon et al., 2008). Therefore, the effects of RSD-induced inflammation on neurogenesis were examined. To label proliferating neural progenitor cells (NPCs) in the DG of the hippocampus, BrdU was injected on the last 3 days of RSD, and $\mathrm{BrdU}^{+}$cells in the DG were determined $0.5 \mathrm{~d}$ after the completion of RSD. Figure $5 A$ shows representative images of
BrdU labeling in the DG. The total number of $\mathrm{BrdU}^{+}$cells in the DG did not differ significantly between RSD and CON mice $0.5 \mathrm{~d}$ after stress (Fig. $5 B$ ).

In a related study, the number of cells expressing DCX, an early neuronal marker, in the DG was also determined. Figure $5 C$ shows representative images of DCX labeling in the DG of CON and RSD mice. At $0.5 \mathrm{~d}$ after RSD, there was no difference in the number of $\mathrm{DCX}^{+}$cells between the treatment groups (Fig. 5D). Next, morphological analysis of the $\mathrm{DCX}^{+}$cells (Zhao et al., 2006) was used to differentiate cells by maturity (i.e., mature vs immature $\mathrm{DCX}^{+}$cells). Representative images of a DCX-labeled mature and immature neuron are shown (Fig. 5E). Again, there was no significant difference in the number of immature or mature neurons between RSD and CON at $0.5 \mathrm{~d}$ after RSD (Fig. 5F). These results indicate that the total number of proliferating cells and the total number of young neurons in the DG were unaffected by RSD at $0.5 \mathrm{~d}$. 
A

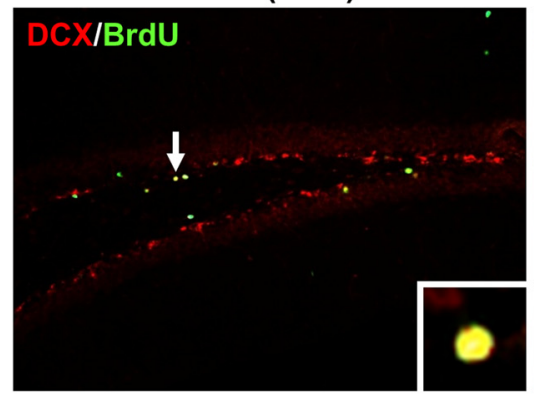

$\operatorname{RSD}(10 \mathrm{~d})$

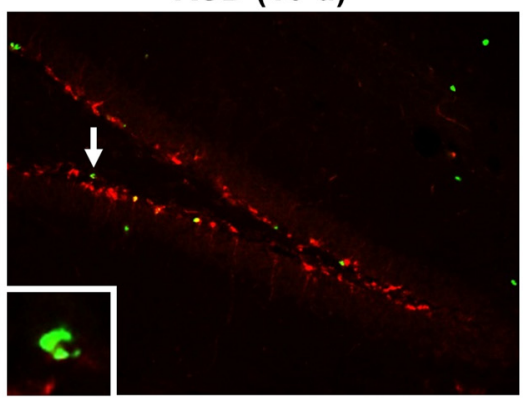

B

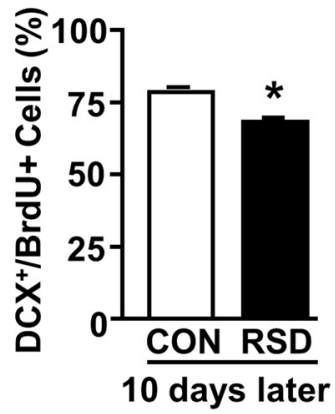

Figure 6. Reduced proliferating neurons in the hippocampus $10 \mathrm{~d}$ after RSD. Mice were subjected to six cycles of RSD or left undisturbed as CONs. BrdU was injected during the last three cycles of social defeat. $B r d U^{+}$and $D C X^{+}$cells were determined in the $D G 10$ d later $(n=6) . A$, Representative images of BrdU/DCX double labeling in the $D G$ are shown. The insets represent a BrdU ${ }^{+} / D C X^{+}$ cell (yellow) and BrdU ${ }^{+} / D C X^{-}$cell (green). B, Percentage of BrdU ${ }^{+}$cells that were also DCX ${ }^{+}$in the DG. Bars represent the mean \pm SEM. ${ }^{*} p<0.05$. means are significantly different from CON.

A

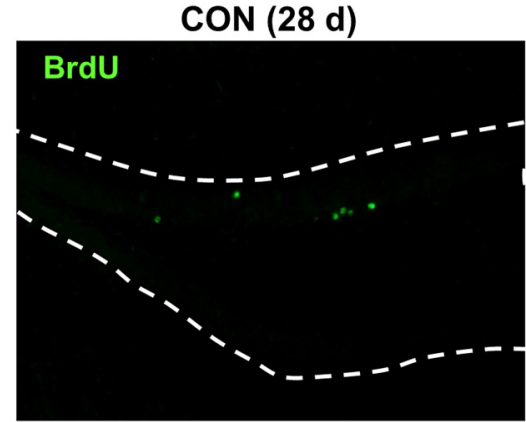

C

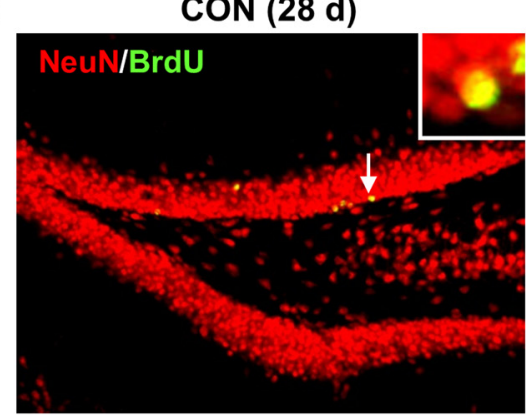

E

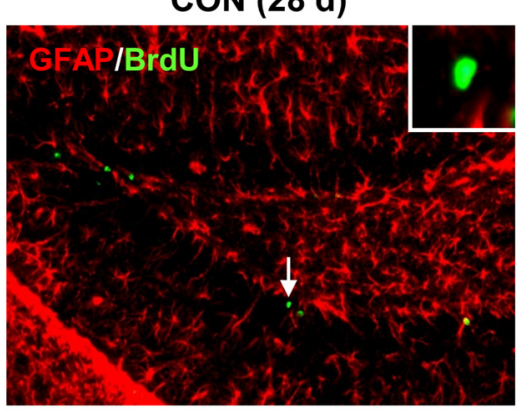

RSD (28 d)

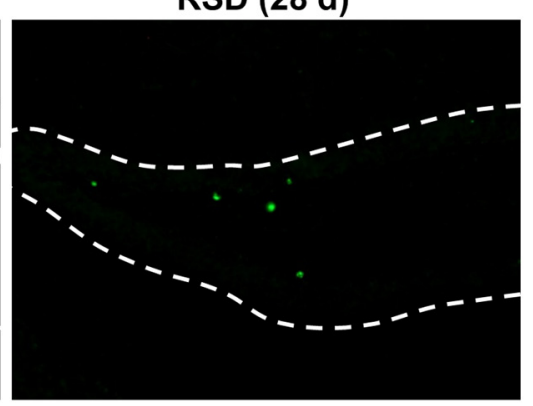

$\operatorname{RSD}(28 \mathrm{~d})$

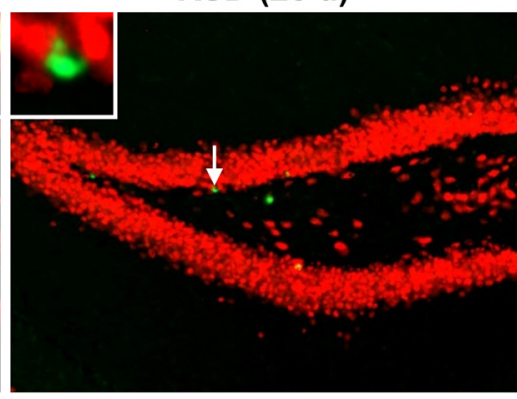

$\operatorname{RSD}(28 \mathrm{~d})$

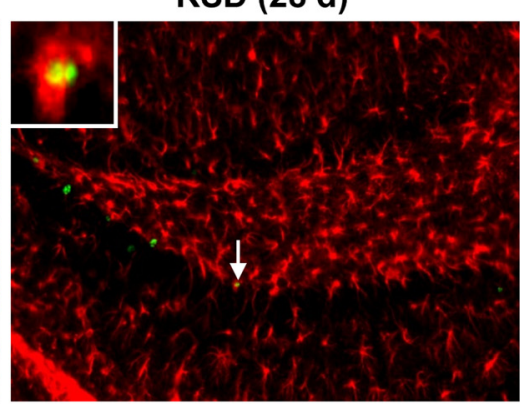

B

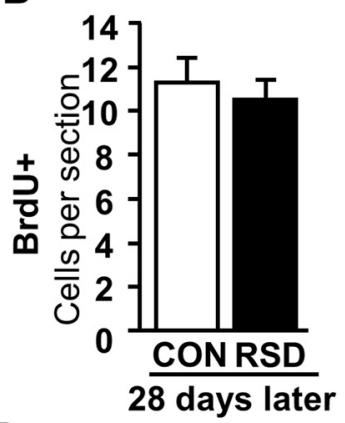

D
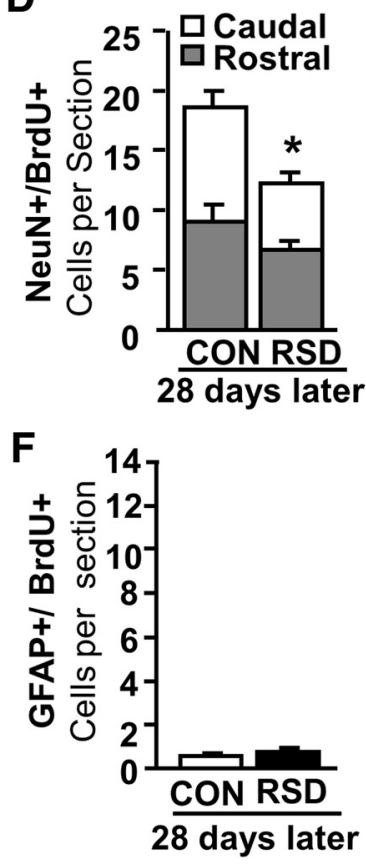

Figure 7. Impaired development of hippocampal NPCs into mature neurons $28 \mathrm{~d}$ after RSD. Mice were subjected to six cycles of RSD or left undisturbed as CONs. BrdU was injected during the last three cycles of social defeat. BrdU ${ }^{+}$, NeuN ${ }^{+}$, and GFAP ${ }^{+}$cells were determined 28 d later $(n=6) \cdot A$, Representative images of BrdU labeling are shown in the DG. $B$, Quantification of BrdU ${ }^{+}$cells per section of the hippocampus. C, Representative images of NeuN/BrdU labeling are shown in the DG. The arrows show the cell depicted in the inset. $D$, Quantification of NeuN ${ }^{+} / B r d U{ }^{+}$cells per section of the hippocampus with rostral-caudal distinction. $\boldsymbol{E}$, Representative images of GFAP/BrdU labeling are shown in the DG. The arrows show the cell depicted in the inset. $\boldsymbol{F}$, Quantification of $\mathrm{GFAP}^{+} / \mathrm{BrdU}^{+}$cells per section of the hippocampus. Bars represent the mean \pm SEM. ${ }^{*} p<0.05$, means are significantly different from CON.

Reduced young neurons in the hippocampus $10 \mathrm{~d}$ after RSD These findings indicated no initial difference in the number of new BrdU ${ }^{+}$cells $0.5 \mathrm{~d}$ after RSD. Nonetheless, the fate of the NPCs may differ with time after RSD. Therefore, to assess the effects of RSD on the phenotypic fate of the hippocampal NPCs, mice were injected with BrdU on the final 3 days of social defeat, and the expression of DCX and BrdU was determined in the DG $10 \mathrm{~d}$ after the completion of RSD (Fig. 6). 
Social Avoidance Assessment 28 days following RSD

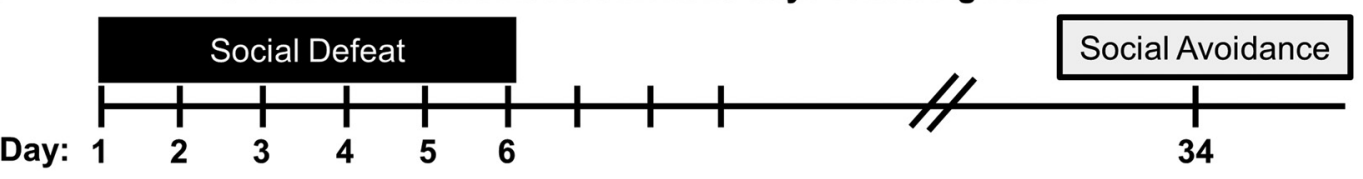

B

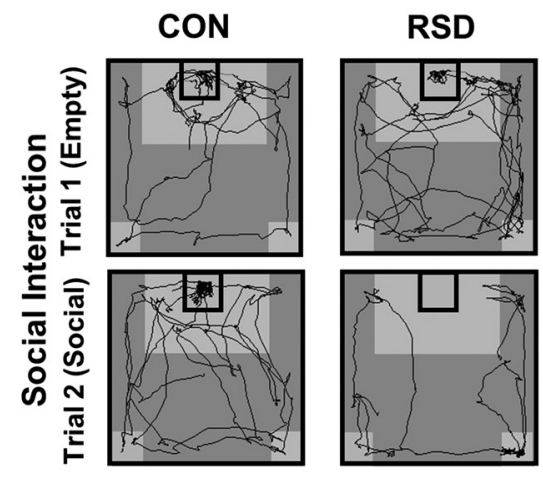

C

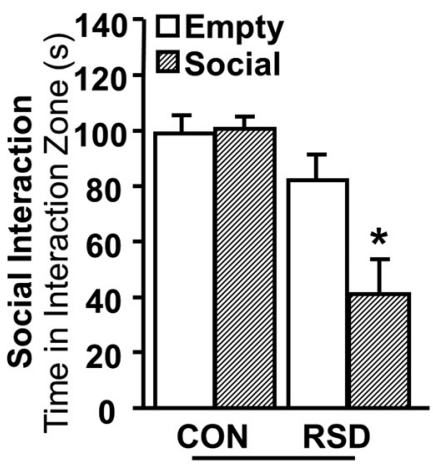

28 days post-RSD
D

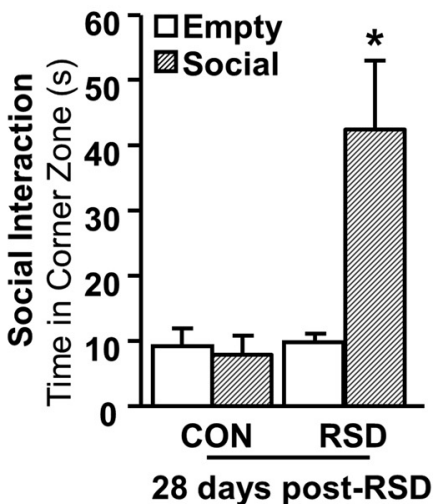

Figure 8. Social avoidance behavior was present $28 \mathrm{~d}$ after RSD. Mice were subjected to six cycles of RSD or left undisturbed as CONs, and social interaction was determined $28 \mathrm{~d}$ later ( $n=14)$. $A$, Representative time line of the experiment is shown. B, Interaction paths are shown for the Empty (Trial 1, top) and Social (Trial 2, bottom) trials. C, Time spent in the interaction zone during the Empty and Social Trials. D, Time spent in the corner zone during the Empty and Social Trials. Bars represent the mean \pm SEM. ${ }^{*} p<0.05$, means are significantly different from all other groups.

Figure $6 \mathrm{~A}$ shows representative double labeling of BrdU and DCX in the DG $10 \mathrm{~d}$ after RSD. The insets highlight a $\mathrm{DCX}^{+} /$ $\mathrm{BrdU}^{+}$cell from a CON (left) and $\mathrm{DCX}^{-} / \mathrm{BrdU}^{+}$cell from an $\mathrm{RSD}$ (right) mouse. The proportion of $\mathrm{BrdU}^{+}$cells that colocalized with $\mathrm{DCX}^{+}$was reduced in mice exposed to RSD compared with CON mice $(p<0.05$; Fig. $6 B)$. Similar to the $0.5 \mathrm{~d}$ results, the total number of BrdU ${ }^{+}$cells was unaffected by RSD (data not shown). Together, RSD significantly reduced the proportion of NPCs that upregulated the early neuronal marker DCX at $10 \mathrm{~d}$ after injection.

\section{Impaired differentiation of hippocampal NPCs into mature neurons $28 \mathrm{~d}$ after RSD}

Because there was a reduction in the number of $\mathrm{BrdU}^{+}$cells that co--localized with the early neuronal marker DCX $10 \mathrm{~d}$ after RSD (Fig. 6B), it was possible that RSD may have reduced the neurogenic capacity of the hippocampal NPCs. To test this idea, mice exposed to RSD were injected with BrdU during the last three cycles of social defeat, and the brain was collected and processed $28 \mathrm{~d}$ later. This time point allowed enough time for the BrdU-labeled NPCs to fully express mature phenotypic markers (Brown et al., 2003), such as NeuN (mature neurons) or GFAP (astrocytes). BrdU ${ }^{+}$cells from sections collected $28 \mathrm{~d}$ after RSD were labeled for NeuN (Fig. 7C) and GFAP (Fig. 7E). The total number of $\mathrm{BrdU}^{+}$cells at this time point was not different between CON and RSD groups (Fig. 7 $A, B$ ). Nonetheless, the number of $\mathrm{BrdU}^{+}$cells in the caudal and rostral DG that colocalized with the mature neuronal marker $\mathrm{NeuN}$ was reduced in mice exposed to $\operatorname{RSD}\left(F_{(1,18)}=96.54, p<0.05\right.$; Fig. $\left.7 C, D\right)$. Moreover, this reduction in $\mathrm{NeuN}^{+} / \mathrm{BrdU}^{+}$cells $28 \mathrm{~d}$ after RSD was more pronounced in the caudal hippocampus $(p<0.05)$. No differences were detected in the number of $\mathrm{BrdU}^{+}$cells that colocalized with GFAP (Fig. $7 E, F$ ). Overall, these findings indicate that the neuronal differentiation of NPCs that proliferated during RSD was impaired.

\section{Social avoidance was maintained $28 \mathrm{~d}$ after RSD}

Results from the neurogenesis studies here indicate significant reduction in the maturation of NPCs in the caudal hippocampus after
RSD. Existing literature on hippocampal anatomy indicates that the caudal hippocampus is involved in emotion and behavior regulation (Fanselow and Dong, 2010). Furthermore, afferents from the ventral hippocampus have been found to regulate depressive-like behavior, as marked by increased social avoidance (Bagot et al., 2015). In line with this finding, previous work from our laboratory and others has shown that RSD increases social avoidance (Wohleb et al., 2013; Donahue et al., 2014). Therefore, to examine the long-term role of RSD-induced impaired neurogenesis on affective functioning (depressive-like behavior), mice were tested on the social avoidance task $28 \mathrm{~d}$ after RSD (timeline depicted in Fig. 8A). The test consisted of two trials. Trial 1 consisted of an empty cage (Empty Trial), whereas Trial 2 consisted of a cage housed by a social conspecific (Social Trial; Fig. $8 B$ ). There was a significant trial $\times$ stress interaction effect on both duration in the interaction zone $\left(F_{(1,27)}=7.39\right.$, $p<0.05$; Fig. $8 C)$ and duration in the corner zone $\left(F_{(1,27)}=9.89\right.$, $p<0.01$; Fig. $8 D$ ). These trial $\times$ stress interactions were characterized by significant reduction in social behavior in the RSD group during the Social Trial. For instance, RSD significantly reduced interaction duration $(p<0.05$; Fig. $8 C)$ and increased corner duration $(p<0.05$; Fig. $8 D)$ during the Social Trial. These results demonstrate RSD-induced social avoidance that persisted at least $28 \mathrm{~d}$ after RSD.

Minocycline intervention attenuated RSD-induced microglia activation and monocyte recruitment

Our results indicate that microglia activation, monocyte recruitment, and neuroinflammatory signaling are temporally associated with spatial memory impairments and co-occur in brain regions that mediate spatial learning and memory. Thus, minocycline, an antiinflammatory agent and purported microglia inhibitor (Henry et al., 2008), was used to determine the role of neuroinflammation in each of these stress-induced events. First, to assess the effect of minocycline on neuroinflammatory signaling in the DG, microglial Iba-1 expression was determined. In vehicle-treated mice, RSD altered microglia morphology that was characterized by increased soma size and thickened cell processes (Fig. 9A). This change in morphology 
A

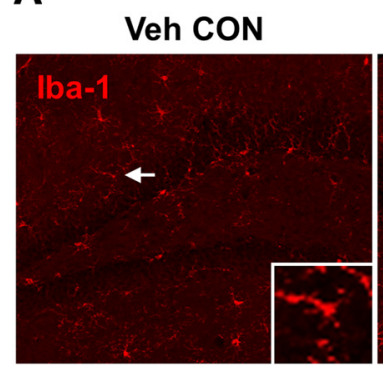

C

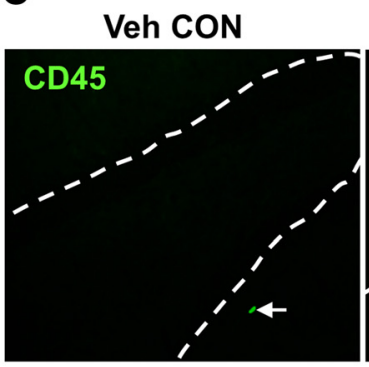

E

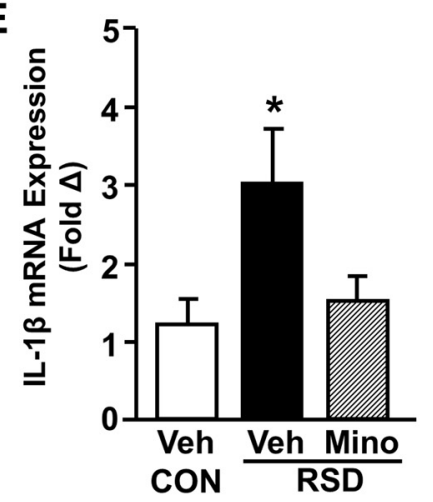

Veh RSD

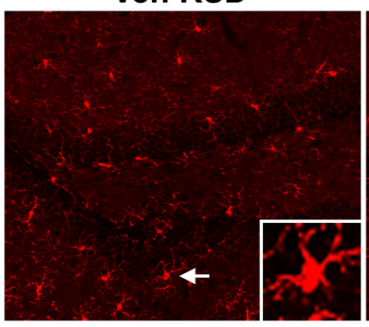

Veh RSD
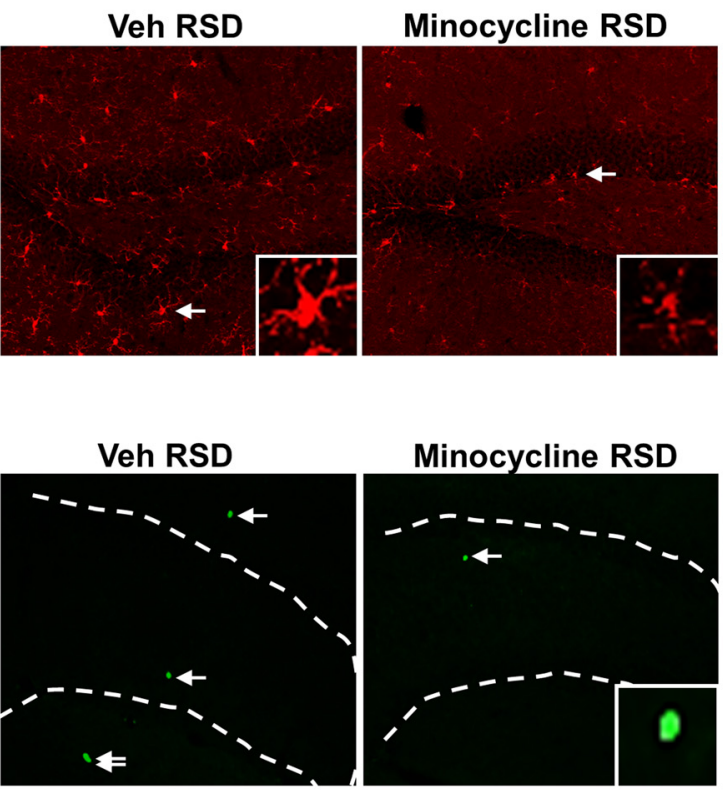

B

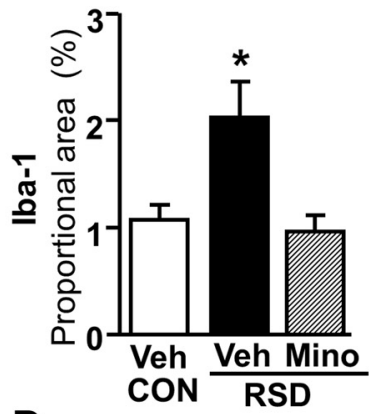

D

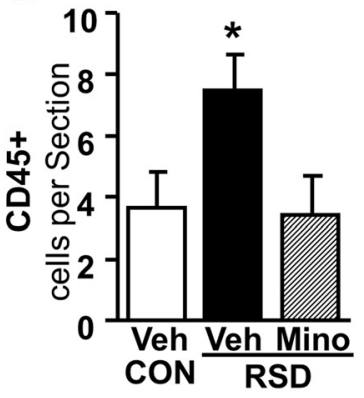

Figure 9. Minocycline intervention attenuated RSD-induced microglia activation and monocyte recruitment. Mice were subjected to six cycles of RSD or left undisturbed as CONs. Minocycline (90 mg/kg) was administered in drinking water throughout the $6 \mathrm{~d}$ of RSD. $\boldsymbol{A}$, Representative images of lba- 1 labeling in the DG are shown. $\boldsymbol{B}$, Proportional area quantification of Iba-1. $\boldsymbol{C}$, Representative images of CD45 labeling in the DG are shown. $\boldsymbol{B}$, Quantification of CD45 ${ }^{+}$cells. $\boldsymbol{E}$, A coronal brain section was collected 14 h after the last cycle of stress, and the mRNA level of IL- $1 \beta$ was determined. Bars represent mean \pm SEM. ${ }^{*} p<$ 0.05 , means are significantly different from CON.

was associated with a significant increase in Iba-1 proportional area. For instance, there was a significant main effect of condition on Iba-1 proportional area $\left(F_{(2,9)}=6.79, p<0.05\right)$ that was characterized by a significant increase in vehicle-treated RSD mice $(p<0.05$; Fig. $9 B)$ that was not detected in minocycline-treated RSD mice $(p=0.765)$. Thus, RSD increased Iba-1 proportional area that was blocked by minocycline.

Because previous work has implicated RSD-induced microglia activation in the recruitment of inflammatory monocytes to the brain (Wohleb et al., 2014b), the effect of minocycline on the presence of $\mathrm{CD} 45^{+}$monocytes in the brain was determined next. As reported here previously, RSD appeared to increase brain monocytes in vehicle-treated mice (Fig. 9C). Consistent with this finding, there was a significant effect of condition on $\mathrm{CD} 45^{+}$cell number $\left(F_{(2,17)}=3.63, p=0.052\right.$; Fig. $\left.9 D\right)$, with a significant increase in vehicle-treated RSD mice $(p<0.05)$ that was not detected in minocycline-treated RSD mice ( $p=0.886)$. Next, IL- $1 \beta$ mRNA was determined in the brain after RSD. There was a significant main effect of condition on IL- $1 \beta \operatorname{mRNA}\left(F_{(2,24)}=6.12, p<0.01\right.$; Fig. $9 E)$, with a significant increase in vehicle-treated RSD mice $(p<0.01)$ that was not detected in minocycline-treated
RSD mice $(p=0.564)$. These results indicate that minocycline inhibited microglia activation and prevented monocyte recruitment to the brain after RSD.

\section{Minocycline prevented spatial memory impairments after RSD}

Next, the effect of minocycline treatment on stress-induced memory deficits was determined. To do this, mice were trained on the Barnes maze for $4 \mathrm{~d}$ before being exposed to RSD with or without minocycline treatment. Mice were then tested for spatial memory recall at 1 and $2 \mathrm{~d}$ after RSD (Fig. 10A). The groups showed no difference in latency $\left(F_{(2,19)}=0.621, p=0.549\right.$; Fig. $10 B)$ or errors $\left(F_{(2,19)}=518, p=0.606\right.$; Fig. $\left.10 C\right)$ during the acquisition phase. However, during the testing phase, there was a significant effect of condition on latency $\left(F_{(2,19)}=5.606, p<\right.$ 0.05; Fig. $10 B)$ and errors $\left(F_{(2,19)}=4.079, p<0.05\right.$; Fig. $\left.10 C\right)$, in which vehicle-treated RSD mice exhibited increased latency and errors on all testing days ( $p<0.05$ for all) but minocyclinetreated RSD mice did not $(p>0.40$, for all). These data show that inhibition of neuroinflammatory activation by minocycline prevented RSD-induced spatial memory recall deficits. 
Memory Recall Assessment in the Barnes Maze

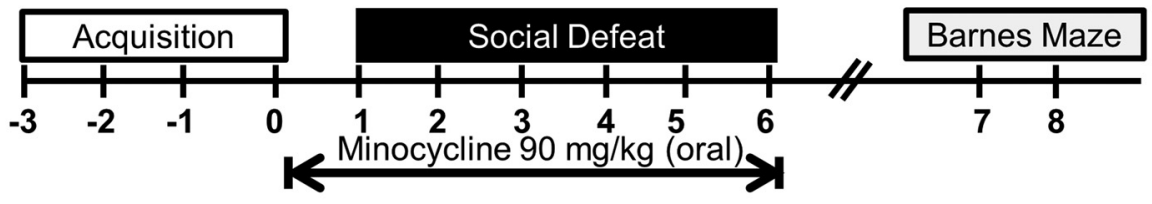

B

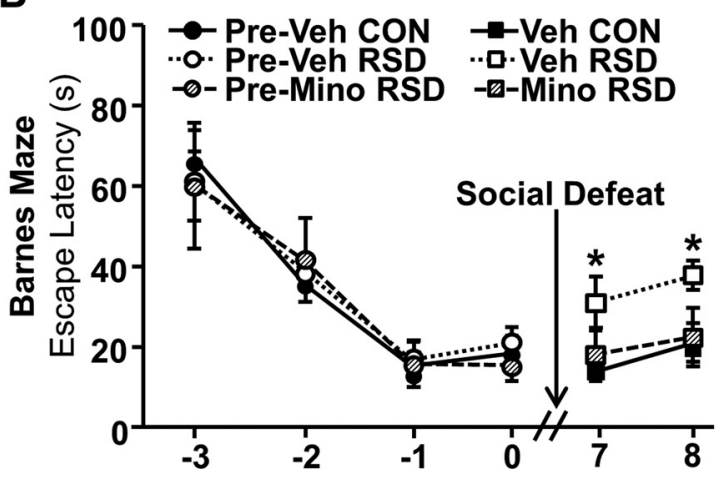

C

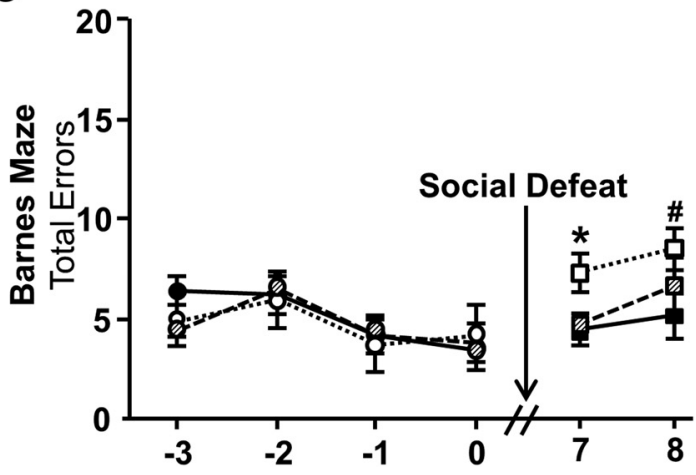

Figure 10. Minocycline prevented spatial memory impairments after RSD. Mice were trained on the Barnes maze to acquire learning before social defeat (Pre-Veh CON, Pre-Veh RSD, and Pre-Mino RSD). The Pre-Mino RSD group received minocycline $(90 \mathrm{mg} / \mathrm{kg}$ ) in drinking water $1 \mathrm{~d}$ before RSD and continued throughout the RSD period. Mice were subjected to six cycles of social defeat (Veh RSD and Mino RSD) or left undisturbed as CONs (Veh CON), and memory recall was determined on D7 and D8. $A$, Representative time line of cognitive assessment in the Barnes maze after RSD $(n=6-9)$. Escape latency $(\boldsymbol{B})$ and errors $(\boldsymbol{C})$ are shown before and after RSD exposure. ${ }^{*} p<0.05$, means are significantly different from CON mice; \#p $=0.06$, mean tended to be different from CONs.

\section{Minocycline did not prevent persistent social avoidance or long-term deficits in NPC differentiation}

We show that RSD has a long-term effect on social avoidance and neuronal cell fate. Therefore, we next sought to determine whether minocycline blocked the effects of RSD on social behavior and NPC differentiation. To do this, mice were administered minocycline during RSD and were injected with BrdU over the last three cycles of social defeat. Then, social behavior was determined 28 d later, and brains were collected for BrdU immunohistochemistry (Fig. 11A). As reported previously (Wohleb et al., 2014a), there was a significant effect of trial on interaction time $\left(F_{(1,20)}=6.214, p<0.05\right.$; Fig. $\left.11 B\right)$, in which CON mice spent significantly more time in interaction in the Social Trial compared with the Empty Trial $(p<0.05)$. This social preference was not detected in either vehicle-treated $(p=0.833)$ or minocycline-treated ( $p=0.594)$ RSD mice. Thus, treatment with minocycline did not prevent reduced social preference in RSD mice. Next, hippocampal brain sections were labeled for BrdU and NeuN. As shown previously, the majority of BrdU ${ }^{+}$ cells in CON mice started expressing the mature neuronal marker (NeuN) by this $28 \mathrm{~d}$ time point, and this neuronal differentiation appeared to again be attenuated by RSD (Fig. 11C). Analysis of these differences revealed a main effect of condition on the percentage of $\mathrm{BrdU}^{+}$cells that were $\mathrm{NeuN}^{+}\left(F_{(1,19)}=5.287, p<\right.$ 0.05 ; Fig. $11 D)$, in which both vehicle-treated $(p<0.05)$ and minocycline-treated $(p<0.01)$ RSD mice showed significant reduction compared with vehicle CON mice. Thus, long-term deficits in social behavior and NPC differentiation after RSD were not prevented by minocycline treatment.

\section{Discussion}

We extend our previous findings on stress and neuroinflammation to show that RSD caused pronounced microglia activation and monocyte recruitment within the caudal hippocampus. These changes were associated with disruptions in hippocampaldependent cognition, as evidenced by impaired spatial memory recall. Moreover, RSD caused long-term disruptions in the differentiation of NPCs into neurons at 10 and $28 \mathrm{~d}$ after RSD. Parallel with neuroinflammatory activation, the reduction in neuronal maturation was more pronounced in the caudal hippocampus $28 \mathrm{~d}$ after RSD, at which point social avoidance behavior was also maintained. This is relevant because the caudal hippocampus is a key regulator of mood and certain depressivelike behaviors, such as social avoidance (Lehmann et al., 2013). The role of neuroinflammatory activation in behavioral and neuronal effects of RSD was delineated using minocycline intervention. Minocycline prevented microglia activation and monocyte recruitment within the hippocampus. In addition, minocycline prevented spatial memory deficits after RSD but did not prevent social avoidance behavior or deficits in NPC differentiation. These data highlight neuroinflammatory-dependent and -independent behavioral deficits after RSD. Together, RSD induced neuroinflammatory signaling in the hippocampus, and inhibition of this signaling prevented stress-induced memory impairments independent of neurogenesis.

A novel finding of this study was the increased presence of CD $45^{+}$monocytes in the hippocampus after RSD. We reported previously that $\mathrm{GFP}^{+}$monocytes infiltrate into the hippocampus of bone marrow-chimeric mice (Wohleb et al., 2013). Here we confirm these findings in wild-type mice that were not exposed to myeloablation, thus avoiding chimera-associated variability that could influence the percentage of cells entering the CNS parenchyma. Notably, however, myeloablation by low dose busulfan is not associated with artifactual monocyte recruitment (Kierdorf et al., 2013; Wohleb et al., 2013). Overall, we have consistently detected an influx of $\mathrm{CD} 11 \mathrm{~b}^{+} / \mathrm{CD} 45^{\mathrm{hi}} / \mathrm{Ly} 6 \mathrm{C}^{+}$monocytes into the brain of wild-type mice after RSD (Wohleb et al., 2011, 2013, $2014 \mathrm{a}, \mathrm{c})$. Here, labeling of CD $45^{+}$cells confirmed that the number of monocytes in the hippocampus was increased $0.5 \mathrm{~d}$ after RSD. In addition, this increase in monocyte recruitment was pronounced in the caudal hippocampus, which corresponded with 
higher Iba-1 immunoreactivity of microglia. Consistent with previous studies (Wohleb et al., 2013; Sawicki et al., 2015), the increased presence of macrophages and de-ramified microglia in the hippocampus were associated with elevated mRNA expression of IL- $1 \beta, \mathrm{TNF} \alpha$, and IL- 6 . Because of the relative infrequency of brain macrophages compared with microglia in naive mice, microglia are the primary producers of cytokine mRNA under homeostasis. However, our previous studies suggest that monocyte trafficking during RSD can propagate and enhance cytokine signaling in the brain (Wohleb et al., 2013). Thus, enhanced cytokine mRNA expression in the hippocampus with RSD is driven collectively by microglia activation and monocyte recruitment. Overall, these data reflect pronounced neuroinflammatory activation within the hippocampus after RSD.

Another key finding of the study was that RSD caused impairments in spatial memory performance in the MWM and the Barnes maze. In the MWM, deficits were detected during the probe trial but not during the learning phase, which is indicative of impaired memory recall (Morris, 1984). Notably, moderately impaired performance was also detected in the working memory version of the MWM in the first $3 \mathrm{~d}$ after RSD. Nonetheless, the interpretation of these results was confounded by anxiety-like search patterns observed in the mice during testing. Based on this confound, we aimed to distinguish stress-induced memory impairment from stress-induced anxiety. There-

fore, mice were trained to locate the escape hole during the acquisition phase of the Barnes maze before RSD. The recall test was performed 1 and $2 \mathrm{~d}$ after the last cycle of social defeat. Mice exposed to RSD exhibited impaired memory recall, indicated by increased latency and errors while locating the escape hole. When tested 28 and $29 \mathrm{~d}$ after RSD, the mice no longer showed deficits in memory recall. Together, RSD induced a transient impairment in spatial memory recall that was independent of anxiety and best detected using the Barnes maze assay.

A novel aspect of this study was that RSD reduced the neuronal cell fate of NPCs that proliferated during stress exposure. Surprisingly, RSD did not reduce the proliferation of NPCs or the number of young neurons in the DG. Impaired neurogenesis was evident during fate-mapping of proliferating cells. This revealed that RSD significantly reduced the number of $\mathrm{DCX}^{+} / \mathrm{BrdU}^{+}$cells $10 \mathrm{~d}$ after RSD. Furthermore, the number of $\mathrm{BrdU}^{+}$cells that matured into neurons $\left(\mathrm{NeuN}^{+} / \mathrm{BrdU}^{+}\right)$was reduced $28 \mathrm{~d}$ after RSD. Thus, RSD did not affect the number of proliferating NPCs initially but did reduce the total number of NPCs maturing into neurons that were incorporated into the dentate circuitry.

It is important to note the temporal mismatch between memory deficits and deficits in neurogenesis. For instance, the spatial memory deficits were transient and no longer present $28 \mathrm{~d}$ after RSD. It is likely that neuroinflammatory activation (e.g., increased IL- $1 \beta$ ), more so than altered neurogenesis, contributes to impaired spatial memory. This possibility is underscored by mi-
Social Avoidance Assessment 28 days following RSD

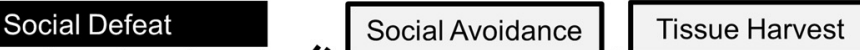

34

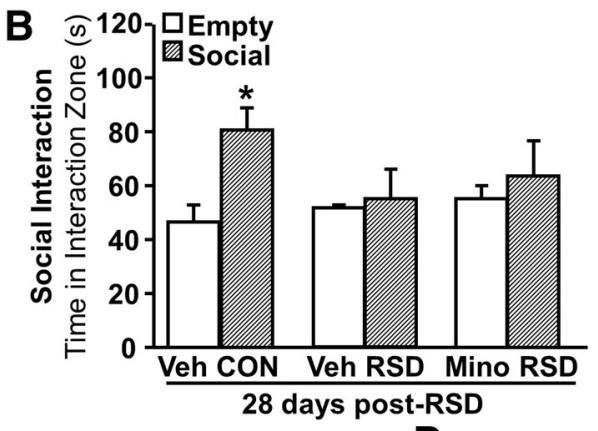

28 Days Post RSD
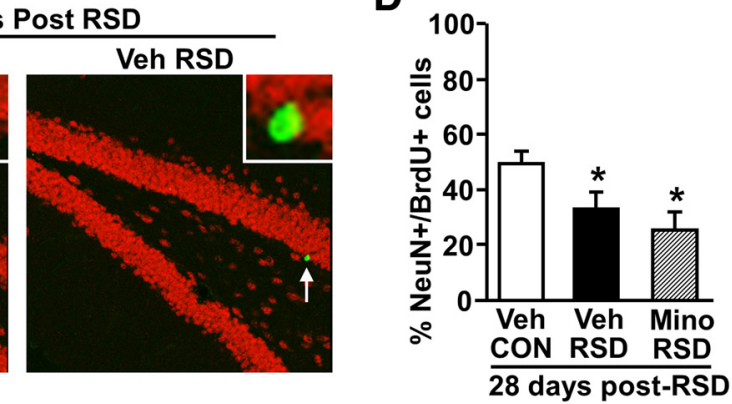

28 days post-RSD

Figure 11. Minocycline did not prevent persistent social avoidance or long-term deficits in NPC differentiation. Mice were (D34) $A$ Representative time line of experimental manipulations $(n=6-9)$. B Time spent in the interaction zone during the Empty and Social Trials was examined. $C$ Representative images of the cell depicted in the inset. $D$, Quantification of $\mathrm{NeuN}^{+} / \mathrm{BrdU}^{+}$cells in the DG. Data represent the mean \pm SEM. ${ }^{*} p<0.05$, means are significantly different from CON mice.

nocycline treatment, which attenuated memory deficits after RSD but had no effect on NPC cell fate. Alteration in physiological levels of IL- $1 \beta$ has also been shown to impair memory in fear conditioning paradigms (Goshen et al., 2007) and promote hippocampal monocyte trafficking (Liu et al., 2015). A prevailing hypothesis is that stress-induced cognitive deficits are attributable to impairments in neurogenesis (McEwen, 1999). The mismatch between acute memory recall deficits and impaired NPC differentiation shown here are inconsistent with this hypothesis. Nonetheless, these data are evidence for ongoing, cumulative effects of RSD on neuronal plasticity. Myriad studies report a reduction in the number of neurons and proliferating NPCs with stress. For example, 4 weeks of chronic isolation stress reduced the number of $\mathrm{DCX}^{+}$cells in the DG and impaired several measures of learning and memory in an IL-1 receptor-dependent manner (Ben Menachem-Zidon et al., 2008). The 4 week span in the study allows enough time for cells to differentiate into neurons and be incorporated into circuitry. This report aligns with our current finding of impaired neuronal maturation in the DG $28 \mathrm{~d}$ after RSD. It is likely that neurogenesis has more profound behavioral implications in stress models that persist at least 4 weeks. Nonetheless, the long-term cognitive affect of RSDinduced impaired neurogenesis is yet to be fully determined.

An important point for discussion is that increased number of monocytes and microglial activation after RSD spatially cooccurred with reduced NPC maturation in the caudal hippocam- 
pus. This selective reduction in neurogenesis in the caudal hippocampus after social stress has been reported previously (Lehmann et al., 2013). Notably, there is a functional dichotomy between the rostral and the caudal hippocampus in cognitive and affective processing (Fanselow and Dong, 2010). The rostral hippocampus is involved in learning, memory, and navigation (Fanselow and Dong, 2010), whereas the caudal hippocampus is involved with the regulation of mood states such as depression. The caudal hippocampus projects to the prefrontal cortex, bed nucleus of the stria terminalis, and subcortical structures associated with the hypothalamic-pituitary-adrenal axis that can indirectly influence learning and memory efficiency (Bannerman et al., 2004). These observations align with the expectation that the caudal rather than rostral hippocampus would exhibit enhanced neuronal activation with stress, leading to region-specific neuroinflammatory activation and altered NPC cell fate.

Previous work shows that social defeat causes persistent social avoidance (Wohleb et al., 2013; Donahue et al., 2014) that is interpreted as depressive-like behavior (Berton et al., 2006; Krishnan et al., 2007; Golden et al., 2011; Ramirez et al., 2015). The association between reduced neurogenesis, elevated inflammation, and increased depressive-like behavior has also been shown in previous studies (Yirmiya and Goshen, 2011; Dinel et al., 2014). Here, we report maintenance of RSD-induced social avoidance and reduction in the number of newly matured neurons, both of which were unaltered by minocycline. These findings suggest that social avoidance observed $28 \mathrm{~d}$ after RSD is unrelated to neuroinflammatory signaling and may be related to reduced neurogenesis in the hippocampus. This observation is consistent with our previous report that a single cycle of social defeat is sufficient to induce social avoidance (Wohleb et al., 2014a) without inducing neuroinflammatory activation (Wohleb et al., 2013).

In summary, RSD promoted hippocampal neuroinflammatory activation that was characterized by increased expression of proinflammatory gene expression along with pronounced microglia activation and monocyte recruitment within the caudal hippocampus. In addition, RSD impaired neurogenesis via reduced neuronal cell fate of NPCs rather than reduced proliferation that is typically reported with stress. Neuroinflammatory activation and impaired NPC differentiation in the hippocampus corresponded with transient spatial memory deficits and persistent social avoidance behavior, respectively. Minocycline prevented RSD-induced neuroinflammatory activation, resulting in a rescue of memory deficits but did not prevent social avoidance or alter impaired NPC cell fate. Collectively, these studies revealed a dichotomy of stress-induced behaviors that were either dependent on neuroinflammatory activation, such as anxiety and memory deficits, or independent of neuroinflammation, such as social avoidance behavior.

\section{References}

Bach ME, Hawkins RD, Osman M, Kandel ER, Mayford M (1995) Impairment of spatial but not contextual memory in CaMKII mutant mice with a selective loss of hippocampal LTP in the range of the theta frequency. Cell 81:905-915. CrossRef Medline

Bagot RC, Parise EM, Peña CJ, Zhang HX, Maze I, Chaudhury D, Persaud B, Cachope R, Bolaños-Guzman CA, Cheer JF, Deisseroth K, Han MH, Nestler EJ (2015) Ventral hippocampal afferents to the nucleus accumbens regulate susceptibility to depression. Nat Commun 6:7062. CrossRef Medline

Bannerman DM, Rawlins JN, McHugh SB, Deacon RM, Yee BK, Bast T, Zhang WN, Pothuizen HH, Feldon J (2004) Regional dissociations within the hippocampus-memory and anxiety. Neurosci Biobehav Rev 28:273-283. CrossRef Medline
Baum A, Cohen L, Hall M (1993) Control and intrusive memories as possible determinants of chronic stress. Psychosom Med 55:274-286. CrossRef Medline

Ben Menachem-Zidon O, Goshen I, Kreisel T, Ben Menahem Y, Reinhartz E, Ben Hur T, Yirmiya R (2008) Intrahippocampal transplantation of transgenic neural precursor cells overexpressing interleukin-1 receptor antagonist blocks chronic isolation-induced impairment in memory and neurogenesis. Neuropsychopharmacology 33:2251-2262. CrossRef Medline

Berton O, McClung CA, Dileone RJ, Krishnan V, Renthal W, Russo SJ, Graham D, Tsankova NM, Bolanos CA, Rios M, Monteggia LM, Self DW, Nestler EJ (2006) Essential role of BDNF in the mesolimbic dopamine pathway in social defeat stress. Science 311:864-868. CrossRef Medline

Brown J, Cooper-Kuhn CM, Kempermann G, Van Praag H, Winkler J, Gage FH, Kuhn HG (2003) Enriched environment and physical activity stimulate hippocampal but not olfactory bulb neurogenesis. Eur J Neurosci 17:2042-2046. CrossRef Medline

Caswell LW, Vitaliano PP, Croyle KL, Scanlan JM, Zhang J, Daruwala A (2003) Negative associations of chronic stress and cognitive performance in older adult spouse caregivers. Exp Aging Res 29:303-318. CrossRef Medline

Dinel AL, Joffre C, Trifilieff P, Aubert A, Foury A, Le Ruyet P, Layé S (2014) Inflammation early in life is a vulnerability factor for emotional behavior at adolescence and for lipopolysaccharide-induced spatial memory and neurogenesis alteration at adulthood. J Neuroinflamm 11:155. CrossRef Medline

Donahue RJ, Muschamp JW, Russo SJ, Nestler EJ, Carlezon WA Jr (2014) Effects of striatal DeltaFosB overexpression and ketamine on social defeat stress-induced anhedonia in mice. Biol Psychiatry 76:550-558. CrossRef Medline

Donnelly DJ, Gensel JC, Ankeny DP, van Rooijen N, Popovich PG (2009) An efficient and reproducible method for quantifying macrophages in different experimental models of central nervous system pathology. J Neurosci Methods 181:36-44. CrossRef Medline

Engler H, Bailey MT, Engler A, Sheridan JF (2004) Effects of repeated social stress on leukocyte distribution in bone marrow, peripheral blood and spleen. J Neuroimmunol 148:106-115. CrossRef Medline

Fanselow MS, Dong HW (2010) Are the dorsal and ventral hippocampus functionally distinct structures? Neuron 65:7-19. CrossRef Medline

Glaser R, Kiecolt-Glaser JK (2005) Stress-induced immune dysfunction: implications for health. Nat Rev Immunol 5:243-251. CrossRef Medline

Golden SA, Covington HE 3rd, Berton O, Russo SJ (2011) A standardized protocol for repeated social defeat stress in mice. Nat Protoc 6:1183-1191. CrossRef Medline

Goshen I, Kreisel T, Ounallah-Saad H, Renbaum P, Zalzstein Y, Ben-Hur T, Levy-Lahad E, Yirmiya R (2007) A dual role for interleukin-1 in hippocampal-dependent memory processes. Psychoneuroendocrinology 32:1106-1115. CrossRef Medline

Heidt T, Sager HB, Courties G, Dutta P, Iwamoto Y, Zaltsman A, von Zur Muhlen C, Bode C, Fricchione GL, Denninger J, Lin CP, Vinegoni C, Libby P, Swirski FK, Weissleder R, Nahrendorf M (2014) Chronic variable stress activates hematopoietic stem cells. Nat Med 20:754-758. CrossRef Medline

Hein AM, Stasko MR, Matousek SB, Scott-McKean JJ, Maier SF, Olschowka JA, Costa AC, O'Banion MK (2010) Sustained hippocampal IL-1beta overexpression impairs contextual and spatial memory in transgenic mice. Brain Behav Immun 24:243-253. CrossRef Medline

Henry CJ, Huang Y, Wynne A, Hanke M, Himler J, Bailey MT, Sheridan JF, Godbout JP (2008) Minocycline attenuates lipopolysaccharide (LPS)induced neuroinflammation, sickness behavior, and anhedonia. J Neuroinflamm 5:15. CrossRef Medline

Janelidze S, Mattei D, Westrin Å, Träskman-Bendz L, Brundin L (2011) Cytokine levels in the blood may distinguish suicide attempters from depressed patients. Brain Behav Immun 25:335-339. CrossRef Medline

Keinan G, Friedland N, Kahneman D, Roth D (1999) The effect of stress on the suppression of erroneous competing responses. Anxiety Stress Coping 12:455-476. CrossRef Medline

Kierdorf K, Katzmarski N, Haas CA, Prinz M (2013) Bone marrow cell recruitment to the brain in the absence of irradiation or parabiosis bias. PLoS One 8:e58544. CrossRef Medline

Koo JW, Duman RS (2008) IL-1beta is an essential mediator of the antineu- 
rogenic and anhedonic effects of stress. Proc Natl Acad Sci U S A 105: 751-756. CrossRef Medline

Kreisel T, Frank MG, Licht T, Reshef R, Ben-Menachem-Zidon O, Baratta MV, Maier SF, Yirmiya R (2014) Dynamic microglial alterations underlie stress-induced depressive-like behavior and suppressed neurogenesis. Mol Psychiatry 19:699-709. CrossRef Medline

Krishnan V, Han MH, Graham DL, Berton O, Renthal W, Russo SJ, Laplant Q, Graham A, Lutter M, Lagace DC, Ghose S, Reister R, Tannous P, Green TA, Neve RL, Chakravarty S, Kumar A, Eisch AJ, Self DW, Lee FS, Tamminga CA, Cooper DC, Gershenfeld HK, Nestler EJ (2007) Molecular adaptations underlying susceptibility and resistance to social defeat in brain reward regions. Cell 131:391-404. CrossRef Medline

Lehmann ML, Brachman RA, Martinowich K, Schloesser RJ, Herkenham M (2013) Glucocorticoids orchestrate divergent effects on mood through adult neurogenesis. J Neurosci 33:2961-2972. CrossRef Medline

Liu X, Yamashita T, Chen Q, Belevych N, Mckim DB, Tarr AJ, Coppola V, Nath N, Nemeth DP, Syed ZW, Sheridan JF, Godbout JP, Zuo J, Quan N (2015) Interleukin 1 type 1 receptor restore: a genetic mouse model for studying interleukin 1 receptor-mediated effects in specific cell types. J Neurosci 35:2860-2870. CrossRef Medline

Mackenzie CS, Smith MC, Hasher L, Leach L, Behl P (2007) Cognitive functioning under stress: evidence from informal caregivers of palliative patients. J Palliat Med 10:749-758. CrossRef Medline

McEwen BS (1999) Stress and hippocampal plasticity. Annu Rev Neurosci 22:105-122. CrossRef Medline

McEwen BS (2012) Brain on stress: how the social environment gets under the skin. Proc Natl Acad Sci U S A 109 [Suppl 2]:17180-17185. CrossRef

McEwen BS (2013) The brain on stress: toward an integrative approach to brain, body and behavior. Perspect Psychol Sci 8:673-675. CrossRef Medline

McKim DB, Patterson JM, Wohleb ES, Jarrett BL, Reader BF, Godbout JP, Sheridan JF (2015) Sympathetic release of splenic monocytes promotes recurring anxiety following repeated social defeat. Biol Psychiatry. Advance online publication. Retrieved January 22, 2016. doi: 10.1016/ j.biopsych.2015.07.010. CrossRef Medline

Miller AH, Maletic V, Raison CL (2009) Inflammation and its discontents: the role of cytokines in the pathophysiology of major depression. Biol Psychiatry 65:732-741. CrossRef Medline

Morris R (1984) Developments of a water-maze procedure for studying spatial learning in the rat. J Neurosci Methods 11:47-60. CrossRef Medline

Morris RG (1981) Spatial localization does not require the presence of local clues. Learn Motiv 12:239-260. CrossRef

O'Connor JC, Lawson MA, André C, Moreau M, Lestage J, Castanon N, Kelley KW, Dantzer R (2009) Lipopolysaccharide-induced depressivelike behavior is mediated by indoleamine 2,3-dioxygenase activation in mice. Mol Psychiatry 14:511-522. CrossRef Medline

Paxinos G, Franklin K (2008) The mouse brain in stereotaxic coordinates, Ed 3. San Diego: Academic.

Powell ND, Sloan EK, Bailey MT, Arevalo JM, Miller GE, Chen E, Kobor MS, Reader BF, Sheridan JF, Cole SW (2013) Social stress up-regulates inflammatory gene expression in the leukocyte transcriptome via betaadrenergic induction of myelopoiesis. Proc Natl Acad Sci U S A 110: 16574-16579. CrossRef Medline

Ramirez K, Shea DT, McKim DB, Reader BF, Sheridan JF (2015) Imipramine attenuates neuroinflammatory signaling and reverses stressinduced social avoidance. Brain Behav Immun 46:212-220. CrossRef Medline

Ramirez K, Niraula A, Sheridan JF (2016) GABAergic modulation with classical benzodiazepines prevent stress-induced neuro-immune dysregulation and behavioral alterations. Brain Behav Immun 51:154-168. CrossRef Medline

Reader BF, Jarrett BL, McKim DB, Wohleb ES, Godbout JP, Sheridan JF (2015) Peripheral and central effects of repeated social defeat stress: Monocyte trafficking, microglial activation, and anxiety. Neuroscience 289:429-442. CrossRef Medline

Sawicki CM, McKim DB, Wohleb ES, Jarrett BL, Reader BF, Norden DM, Godbout JP, Sheridan JF (2015) Social defeat promotes a reactive endothelium in a brain region-dependent manner with increased expression of key adhesion molecules, selectins and chemokines associated with the recruitment of myeloid cells to the brain. Neuroscience 302:151-164. CrossRef Medline

Schnieder TP, Trencevska I, Rosoklija G, Stankov A, Mann JJ, Smiley J, Dwork AJ (2014) Microglia of prefrontal white matter in suicide. J Neuropathol Exp Neurol 73:880-890. CrossRef Medline

Sparkman NL, Buchanan JB, Heyen JR, Chen J, Beverly JL, Johnson RW (2006) Interleukin-6 facilitates lipopolysaccharide-induced disruption in working memory and expression of other proinflammatory cytokines in hippocampal neuronal cell layers. J Neurosci 26:10709-10716. CrossRef Medline

Torres-Platas SG, Cruceanu C, Chen GG, Turecki G, Mechawar N (2014) Evidence for increased microglial priming and macrophage recruitment in the dorsal anterior cingulate white matter of depressed suicides. Brain Behav Immun 42:50-59. CrossRef Medline

Tynan RJ, Naicker S, Hinwood M, Nalivaiko E, Buller KM, Pow DV, Day TA, Walker FR (2010) Chronic stress alters the density and morphology of microglia in a subset of stress-responsive brain regions. Brain Behav Immun 24:1058-1068. CrossRef Medline

Vitaliano PP, Murphy M, Young HM, Echeverria D, Borson S (2011) Does caring for a spouse with dementia promote cognitive decline? A hypothesis and proposed mechanisms. J Am Geriatr Soc 59:900-908. CrossRef Medline

Wohleb ES, Hanke ML, Corona AW, Powell ND, Stiner LM, Bailey MT, Nelson RJ, Godbout JP, Sheridan JF (2011) $\beta$-Adrenergic receptor antagonism prevents anxiety-like behavior and microglial reactivity induced by repeated social defeat. J Neurosci 31:6277-6288. CrossRef Medline

Wohleb ES, Powell ND, Godbout JP, Sheridan JF (2013) Stress-induced recruitment of bone marrow-derived monocytes to the brain promotes anxiety-like behavior. J Neurosci 33:13820-13833. CrossRef Medline

Wohleb ES, McKim DB, Shea DT, Powell ND, Tarr AJ, Sheridan JF, Godbout JP (2014a) Re-establishment of anxiety in stress-sensitized mice is caused by monocyte trafficking from the spleen to the brain. Biol Psychiatry 75:970-981. CrossRef Medline

Wohleb ES, McKim DB, Sheridan JF, Godbout JP (2014b) Monocyte trafficking to the brain with stress and inflammation: a novel axis of immuneto-brain communication that influences mood and behavior. Front Neurosci 8:447. CrossRef Medline

Wohleb ES, Patterson JM, Sharma V, Quan N, Godbout JP, Sheridan JF (2014c) Knockdown of interleukin-1 receptor type-1 on endothelial cells attenuated stress-induced neuroinflammation and prevented anxiety-like behavior. J Neurosci 34:2583-2591. CrossRef Medline

Yirmiya R, Goshen I (2011) Immune modulation of learning, memory, neural plasticity and neurogenesis. Brain Behav Immun 25:181-213. CrossRef Medline

Zhao C, Teng EM, Summers RG Jr, Ming GL, Gage FH (2006) Distinct morphological stages of dentate granule neuron maturation in the adult mouse hippocampus. J Neurosci 26:3-11. CrossRef Medline 